\title{
Habitat Multivariate Design Model Pilot Study
}

\author{
Marc M. Cohen \\ Advanced Projects Branch, Space Projects Division, NASA-Ames Research Center
}


For permission and licensing requests contact:

\author{
SAE Permissions \\ 400 Commonwealth Drive \\ Warrendale, PA 15096-0001-USA \\ Email: permissions@sae.org \\ Tel: $\quad 724-772-4028$ \\ Fax: $\quad 724-772-4891$
}

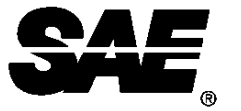

\title{
Global Mobility Database ${ }^{\circledast}$
}

All SAE papers, standards, and selected books are abstracted and indexed in the Global Mobility Database.

For multiple print copies contact:

\author{
SAE Customer Service \\ Tel: $\quad$ 877-606-7323 (inside USA and Canada) \\ Tel: $\quad$ 724-776-4970 (outside USA) \\ Fax: $\quad$ 724-776-1615 \\ Email: CustomerService@sae.org
}

\section{ISSN 0148-7191}

Positions and opinions advanced in this paper are those of the author(s) and not necessarily those of SAE. The author is solely responsible for the content of the paper. A process is available by which discussions will be printed with the paper if it is published in SAE Transactions.

Persons wishing to submit papers to be considered for presentation or publication through SAE should send the manuscript or a 300 word abstract to Secretary, Engineering Meetings Board, SAE.

\section{Printed in USA}




\title{
Habitat Multivariate Design Model Pilot Study
}

\author{
Marc M. Cohen \\ Advanced Projects Branch, Space Projects Division, NASA-Ames Research Center
}

\begin{abstract}
This paper presents a preliminary modeling method, Habitat Multivariate Design Model (HMVDM), to estimate the volume, size, shape, and configuration required for the design of a space habitat. The specific habitat used for this analysis is the "Habot" mobile lunar base concept.

The HMVDM methodology begins with values for mass and volume from quantitative summation tools such as the NASA Office of Biological and Physical Research (OBPR) Crew Accommodations Guide. From these tools, it derives a more detailed analysis of mass and particularly of volume. The estimated volume is input into the model, written as a spreadsheet-based analytical modeling tool. In this pilot study, the diameter of a cylindrical module serves as the single independent variable. The dependent variables include: the number of pressure ports, the floor area, the height of the end dome, the height of the cylindrical portion of the module, the number of floor decks, the floor to floor height, and the volume of vertical circulation.
\end{abstract}

The model affords an array of adjustable evaluation criteria and set point limits to assess the results in the dependent variables. This evaluation provides the ability to analyze the independent variable for which values meet the "requirements" of the mission and habitat design.

\section{INTRODUCTION}

The NASA Exploration Team (NEXT) Human Support Subsystem Working Group (HSSWG) makes the remarkable statement:

There is currently no method to determine, with absolute certainty, the amount of habitable space per crewmember needed for missions beyond LEO.

Until better data is available, designers should plan on allocating a minimum of $16.99 \mathrm{~m}^{3}\left(600 \mathrm{ft}^{3}\right)$ of usable space per crewmember [original emphasis] (NEXT; March, 2002; p. 46)."

This statement is remarkable because it reveals the authors' inability to design architectural space in terms of volume. The referenced NEXT report does not give any basis for this estimate (citing only MSFC Skylab reports from the early 1970s), nor does it reflect a familiarity with volumetric issues, stating the volume to four significant figures by failing to round the SI units to $17 \mathrm{~m}^{3}$. However, this statement is very useful at portraying the state of the art or the state of the technology within the NEXT team as of 2002.

\section{THE SPACE ARCHITECTURE AND HABITABILITY LITERATURE}

What is most significant about this NEXT report is the propensity to make new pronouncements about a mature and complex field of research without scholarly reference to any of that reference. The space architecture, habitability, and human factors literature addresses the issues of designing space habitats in all aspects and dimensions. However, it is beyond the scope of this paper to present this vast literature and explain how it informs this question. Instead, this pilot study focuses exclusively on the question of habitat volume, and the dimensional factors that inform habitat architecture.

\section{THE HABOT}

Finding a systematic and quantifiable approach to answering this question is essential for the Habot. The Habot provides the vehicle of study for this pilot project. "Habot" is a contraction of Habitat and Robot. It constitutes an innovative approach to combine human and robotic exploration capabilities. John Mankins introduced the Habitat Robot (Habot) concept in 2000 (Mankins, 2000; Mankins, 2001). This research began by analyzing Habot in the tradition of mobile base concepts dating from 1971 to the present (Cohen, 2003; Cohen, 2004). 


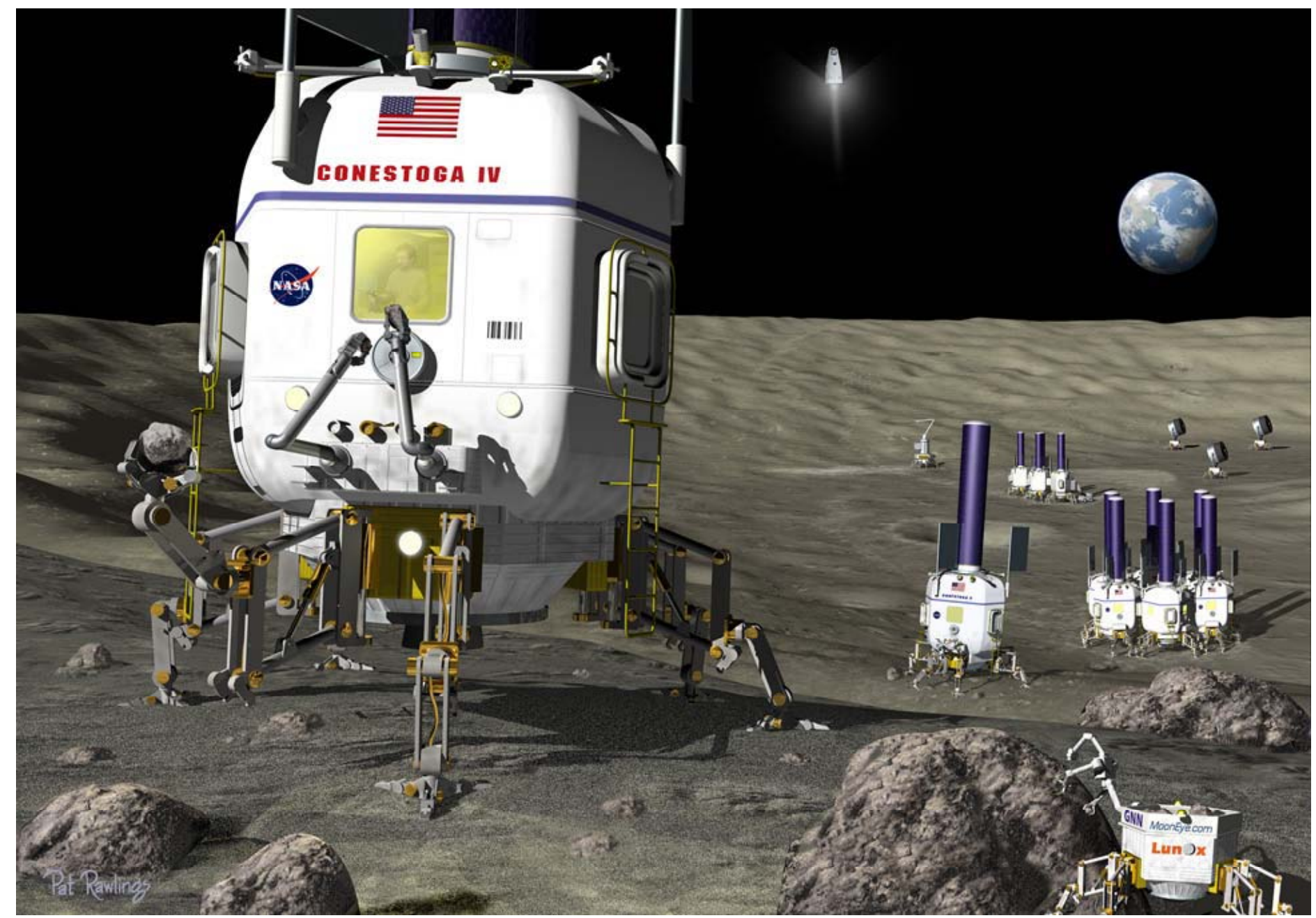

FIGURE 1. Artist's rendering of the "Habot" Mobile Lunar Base concept, by Pat Rawlings, commissioned by Neville Marswell, JPL for John Mankins, NASA Office of Exploration Systems.

The Habot concept consists of a self-mobile habitat that lands autonomously at a specific landing zone on the Moon. It moves under its own power to a lunar base site. More Habots follow, landing at the LZ and then moving to the base site. The Habots cluster together to form a base-habitat complex. They dock together, form pressure seals, and pressurize the complete living environment. After verifying that the Habot base is ready, the crew arrives on the Moon to occupy the Habot base. After carrying out their mission, the crew returns to Earth. The Habots disconnect the base and migrate across the lunar surface to the next mobile lunar base site. There they cluster together again, reconnect to form the base, and verify readiness. A new Habot logistics module may land at the second base site to resupply consumables and bring new equipment. The second crew arrives to carry out the next mission.

The parameters of the Habot mission are as follows. The Habots launch to the Moon over a period of one to two years. After verification of the first Habot mobile base, the first crew arrives. The nominal mission timeline is 100 days, allocated to a primary mission of two lunar day/night cycles (56 Earth Sols). There are 8 sols planned margin for lift-off from the Moon and 36 Earth sols reserve capability. The planned crew size is four astronauts. The baseline number of crew missions is 10 , for a total planned crew time of 560 Earth sols, with a total capability for 1000 crew days on the Moon during those 10 missions.

An artist's rendering of the Habot Concept appears in FIGURE 1. In this version, the modules land on six articulated legs, and then walk away robotically from the landing zone. The Habots cluster together automatically to form a temporary base. The possible module size ranges from about $3 \mathrm{~m}$ to $5 \mathrm{~m}$ diameter. The artist chose to draw the pressure vessels as hexagonal, but a hexagonal prism is a very inefficient structural geometry for a pressure vessel. The pressure vessels are hexagonal only insofar as they evoke three cross-axes separated equally at $60^{\circ}$ of arc (a hexagonal prism of this type is not efficient for a pressure vessel structure). A realistic Habot pressure vessel would be a squat cylinder ("tuna can"). They cluster together automatically to form a temporary base, as shown in the right mid-background 
of FIGURE 1. The possible module size ranges from about 3 to $5 \mathrm{~m}$ diameter.

\section{PILOT STUDY}

This Pilot Study addresses the point of the quotation from the NEXT report: to suggest a method for modeling requirements for habitable volume quantitatively. This pilot study develops a model that offers a way for these key disciplines - Architecture, Engineering, Habitability, and Human Factors to all proceed simultaneously in parallel. It provides a foundation for communication in this domain, where the "hard discipline" engineers may not understand that their work has profound implications for the crew; where architects may not understand the necessity of a logical and analytical framework for their designs, and where the human factors community may not perceive the consequences of simple structural and mechanical design decisions.

The Habitat Multivariate Design Model Pilot Study provides the beginning for such a discussion. It is based upon an Excel workbook format for simplicity of use and ease of accessibility. The purpose is to illuminate the architectural issues pertaining to volume, from which the next phase of the research will extract data that can influence both habitability and structural engineering design.

\section{APPROACH}

The specific aim of this pilot study is to apply a quantitative, computational model to the "Habot" Mobile Lunar Habitat. These models will afford a capability to validate design concepts based upon empirical data and formal logic. The HMVDM is part of a larger project to develop the Habot as a candidate for lunar exploration.

This project involves several multivariable methods to approach this problem. The keystone habitat multivariate design model (HMVDM) is a spreadsheet engineering approach, developed at NASA-Ames that applies to habitat sizing, dimensions, and accommodations of specific architectural features or functions. The model takes an independent variable, and two constants and calculates the results for dependent variables such as the number of circumferential windows or pressure ports or such as the number of floor decks of a given structural depth and floor to floor height that the habitat can accommodate within a specified criteria range. The output data from this model are intended to provide input parameters to a programmable CAD model that can draw a 3-D solid representation of the habitat that falls within the specified criteria ranges for all the dependent variables.
The advantage of these approach is that all the assumptions about area, mass, volume, structure, equipment accommodation and other parameters must be made explicit in the Habitat Multivariate Design Model as an independent variable, a constant, a dependent variable, or as the limits of a criteria range. HMVDM will move space habitat design out of the subjective, "back of the envelope," largely unaccountable engineering culture and make it transparent, readily documented, and accessible to interactive trade analyses between the often competing disciplines of architecture, engineering and habitability.

\section{METHODS: HMVDM}

This methodology evolved through the HMVDM pilot study, which appears below. This primary method addresses the question of how to develop the characteristics, dimensions and other spatial characteristics of habitat under a selected set of constraints. In this study, there are a number of variables, all of which can be readily manipulated to explore the parameters of the problem. The structure of the model is to create a model in Excel in which each line constitutes a record that presents controlled variation in the habitat diameter. From this one series of variations flows a range of results.

FIGURE 2 shows a flow chart of the pilot study's design research methodology. This paper presents this first phase of the pilot study, which comprises the Core HMVDM. The methodology begins at the top of FIGURE 2 with a compilation of summation data, typically from sources such as the OBPR Crew Resource Accommodations Model, Equivalent Systems Mass models, and other metrics. The summation data flows into a schematic step that identifies functions, activities, operations and crew accommodations that manifest in volumetric architectural and physical elements such as pressure ports, vertical circulation and floor decks. These schematic elements inform directly the Core HMVDM.

\section{DEFINED QUANTITATIVE ELEMENTS}

Within the Core HMVDM, as shown in FIGURE 2, the model is formulated on three paths: defining the independent variables, defining the desired dependent variables, and setting the range of numerical expressions, constants, and constraint criteria accordingly. For each specific habitat geometry and mission, it would be necessary to define each of these quantitative aspects differently, and to write specific code for that geometry. This pilot study is specific only to the Habot mobile lunar base concept. 


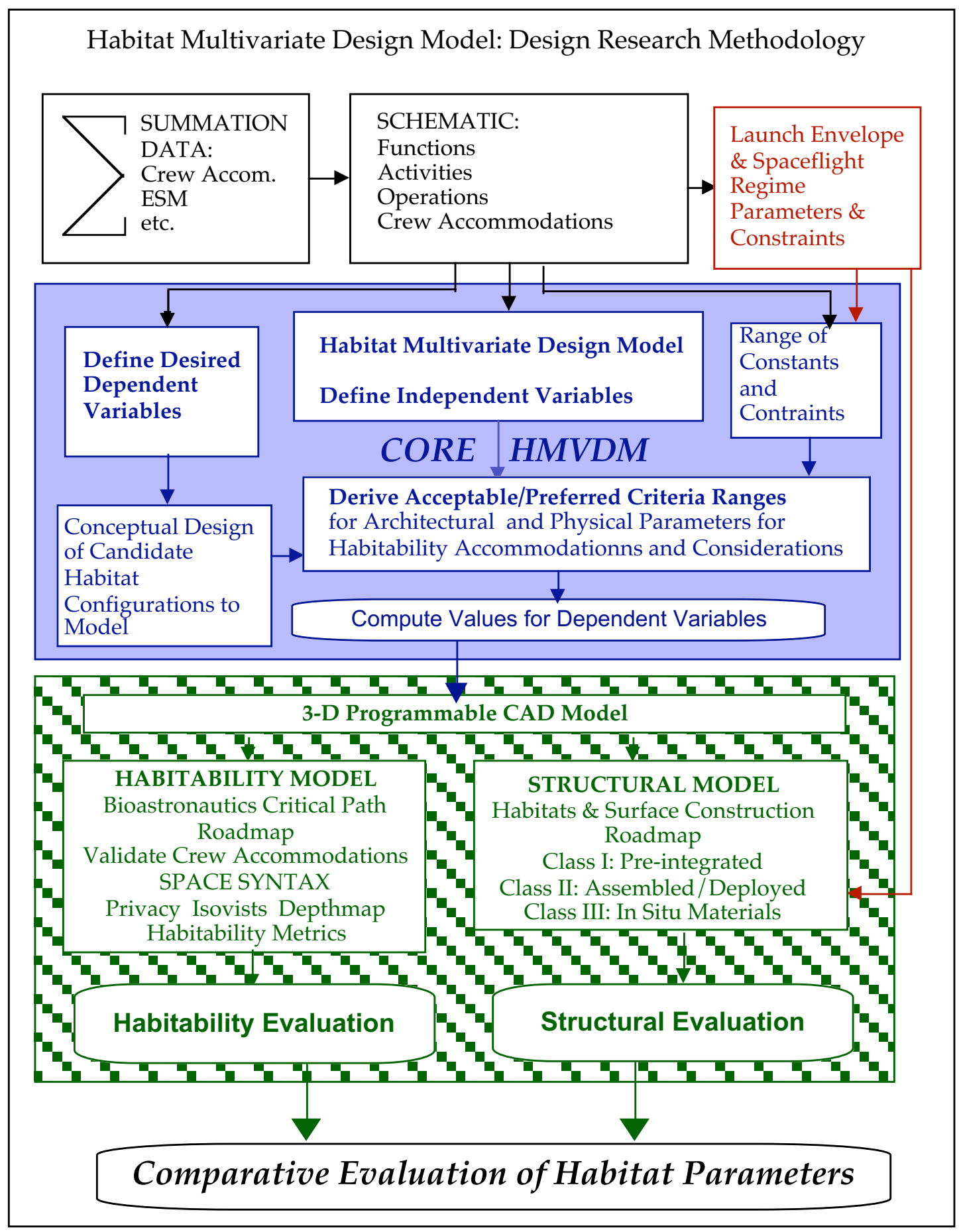

FIGURE 2: HMVDM Project Design Research Methodology. The Pilot Project consists of a preliminary test of the CORE HMVDM (blue) segment. 
Central to this method is defining the independent variable. In this study, the independent variable is the Habot diameter, within a range from $3.5 \mathrm{~m}$ to $5.0 \mathrm{~m}$. The Habot is conceived here as a squat cylinder. The hexagonal floor plan implied in FIGURE 1 is not realistic as a pressure vessel because structural $120^{\circ}$ degree corners impose too great a mass and complexity penalty. The question of habitat diameter is a primary issue because it goes to habitat size, and the allocation of functional volume among Habots. In a Habot mobile base cluster, this issue adds up to predicting the total number of Habot units that would need to be landed on the Moon.

The pilot project to date appears on the upper half of the flowchart. The mass and volume budget summation data appear in TABLE 1, based upon the NASA Office of Biological and Physical Research (OBPR) "Mass Factors for Crew Accommodations in Various Mission Types" model. The schematic design concept is the initial walking Habot imagery that appears in FIGURE 2. The launch envelope and spaceflight regime resides in a set of assumptions described below. TABLE 2 demonstrates the pilot project of the Habitat Multivariate Design Model (HMVDM) for the original Habot concept, all of which is displayed in the blue box. This article reports progress through the core HMDVM phase one (solid gray block in FIGURE 1).

The lower half of the flow chart shows the next steps in developing this methodology. After completing the design research described above, the next step in the research appears in the green box. This step centers upon developing a programmable CAD model that imports all the values from the HMVDM and uses them to construct a 3-D solid representation of the habitat. With that model in hand, it will be possible to take two further research paths to assess habitability and structure. Ultimately, this second phase of the research will enable the capability to do a comparative, quantitative and qualitative analysis of habitat architecture that incorporates both habitability and structural considerations.

This pilot study represents only the Core HMVDM. After proving and verifying the Core, development of the second phase will begin. A quick synopsis of the proposed second phase will explain the use and applications of this model. The intent is to provide a basis for comparing the habitability and structural design considerations, constraints, impacts, and demands in the habitat architecture. The habitability analysis path will employ the quantitative modeling of human spatial habitability (Batty, 2001; Benedikt, 1979; Stuster, 1986; Turner, Penn, 1999; Wise et al, 1988). The structural analysis path will involve the development of structural calculations that shape the design of the habitat module.
The larger Habot Project will require much more comprehensive analysis with the HMVDM tool, and all the conventional sizing and mass estimation tools (ESM, Life Cycle Cost, BVAD, etc) to obtain a specific Habot habitat design with a high level of confidence.

\section{RESEARCH DESIGN}

The research design for the HMDVM centers on the data structure within the spreadsheet. The data structure takes the form of a record that includes a combination of real numbers, integers, Boolean logic arguments, and alphanumeric values. Within this record four data constructs occur: the independent variable, the constants, the dependent variable and the preferred evaluation criteria.

\section{RECORD DATA STRUCTURE}

The organization of the model is based upon the data structure of a record that is repeated on each line. The reason for this particular data structure is that for a given value of the independent variable, it is efficient to compute the output values for all the dependent variable on that line of the spreadsheet. This record format makes all the assumptions and formulas explicit and easy to follow.

Independent Variable -- For each specific analysis, the HMVDM accommodates one independent variable, which appears as a real number in the far left column. It is possible to define the independent variable within a range with a value range and specific increment size. In this model, there is the capability to work with independent variables, constants and dependent variables. For each page of the worksheet, there is one independent variable. In the example shown in the pilot study, there are two constants: volume and number of radial pressure ports. Within code algorithms in the cells, there is the opportunity to develop a variety of dependent variable outputs. In the pilot study, the model uses seven dependent variables.

Dependent Variables -- The HMVDM permits an unlimited number of dependent variables, the output values of which appear in the body of the spreadsheet. For each dependent variable, there is a coded algorithm written in Excel programming functions. The pilot study incorporated seven dependent variables. The dependent variables are embodied in Boolean logic statements that output a specific result as a real number and an alphanumeric indicator, shown as a symbol comprised of three left pointing arrows " $<<"$. This graphical indicator suffices for the pilot study as a single worksheet, but it also affords a placeholder for future Boolean values that can pass to a larger analytical model. 


\section{FUNCTION CALLS}

The Excel Worksheet incorporates two kinds of function calls: constants and preferred criteria for the dependent variables.

Constants -- In the pilot study, the HMVDM is set up to employ two constants: the constant volume of the habitat pressure vessel or module and the number of radial pressure port penetrations around the circumference of the "Tuna Can" type module. Constants include real numbers and integer values.

Preferred Criteria Array -- Across the bottom of the HMVDM spreadsheet there appears an array of cells in which the researcher can enter hypothetical or test values for each of the input parameters that may affect the dependent variables, providing input range values for their formulas. These preferred evaluation criteria may be real numbers or integers.

\section{THE PILOT STUDY}

The specific application of this formulation of the HVMDM is to determine the optimal diameter for the Habot module. In the model, the independent variable represents habitat diameter, in a probable range from $2.5 \mathrm{~m}$ to $6.0 \mathrm{~m}$, in increments of $0.25 \mathrm{~m}$. The two constants are volume at and the number of radial pressure port or window penetration positions at specifically defined circumferential spacing. The input of such constraints and constants occurs in the data array at the bottom of the page. The results for the dependent variables appear in the designated cells in the Record for each value of the independent variable. Beside each of the dependent variable values, a graphical indicator "<<" appears to indicate the values that fall within the preferred or acceptable range.

One important aspect of this model is that it does not pursue a single, deterministic answer to a complex question or set of questions. Rather, it returns a range of values for each dependent variable. If an acceptable or preferred value results for all of the dependent variables in one or more records, that indicates a response completely "within range" for the corresponding value of the independent variable.

Please refer to the two TABLES 1 and 2. TABLE 1 shows the Pilot Study's application of the OBPR Crew Accommodations Calculation spreadsheet for the 64 Sol baseline mission on the Lunar surface, which corresponds to two lunar day/night cycles with about a $12 \%$ surface stay time margin. The lower part of the table shows the specific values added to new sections based on a separate and independent set of criteria. This calculation yields a total internal pressurized system mass (not including the pressure vessel, hatches or windows) of $7,113.44 \mathrm{~kg}$. The total volume is $98.666 \mathrm{~m}^{3}$, which is the figure of merit for the pilot study.

TABLE 2 presents the HMVDM spreadsheet. The input cell for the constant volume of $100 \mathrm{~m}^{3}$ (rounded up from $98.666 \mathrm{~m}^{3}$ ) appears in the control array at the bottom, top left cell. The other constant value, is six "pressure ports" or window penetrations from the original concept of a hexagonally module. This hexagonal, hexapod Habot concept appears in FIGURE 2. The shape of the pressure vessel in the picture has no bearing on the cylindrical form in the Pilot Study, however, if there was a compelling reason to use such a peculiar geometry, the model could accommodate it with slight added complexity. Both constants are repeated in the top black banner bar.

TABLE 3 presents the HMVDM with different values for the constants: $50 \mathrm{~m}^{3}$ constant volume and four radial port positions. The reason for TABLE 3 is that the input values for TABLE 2 did not succeed in generating a complete solution. The simplest alternative was to divide the constant volume in half, between two modules.

\section{ASSUMPTIONS}

The HMVDM Pilot Study is build upon a foundation of architectural, input data, arithmetic, and logic assumptions. While some of these assumptions may seem self-evident from various points of view, for the purpose of the Pilot Study, it is essential to state them explicitly where relevant, even at the cost of redundancy.

\section{MASS AND VOLUME ASSUMPTIONS}

The pilot study's point of departure is the OBPR Crew Accommodation model. This model allows the user to select among several mission profiles, selecting a crew size and mission duration. For the pilot study, the author chose four crewmembers on a 64-day lunar mission, based upon two lunar day/night cycles of 56 Earth sols, plus an eight sol planned reserve. This exercise does not address true margins for reliability and redundancy, which would certainly increase the stay time to at least 100 sols. Indeed, if the recent International Space Station (ISS) experience is an indicator, it might be necessary to plan on backup capability of 200 to 400 days in case there was a problem with the Earth return vehicle.

The original OBPR model provides all the elements shown in the rows down through the medical requirements section, derived from NASA's empirical and historical experience of equipment and consumables requirements on actual space missions. The one exception is that for the pilot study, the sleep volume is increased from $0.25 \mathrm{~m}^{3}$ per crewmember in the OBPR model (representing just a sleep restraint sack with a person in it) by a factor of six, to $1.5 \mathrm{~m}^{3}$ per 
crewmember, which represents a private sleeping cabin. However, this value is still smaller than the crew cabins indicated in SKETCHES 1a and 4.
Below the medical requirements row are the elements that the author developed to help complete the OBPR model. These quantities derive from architectural measurements of and estimates of ISS modules.
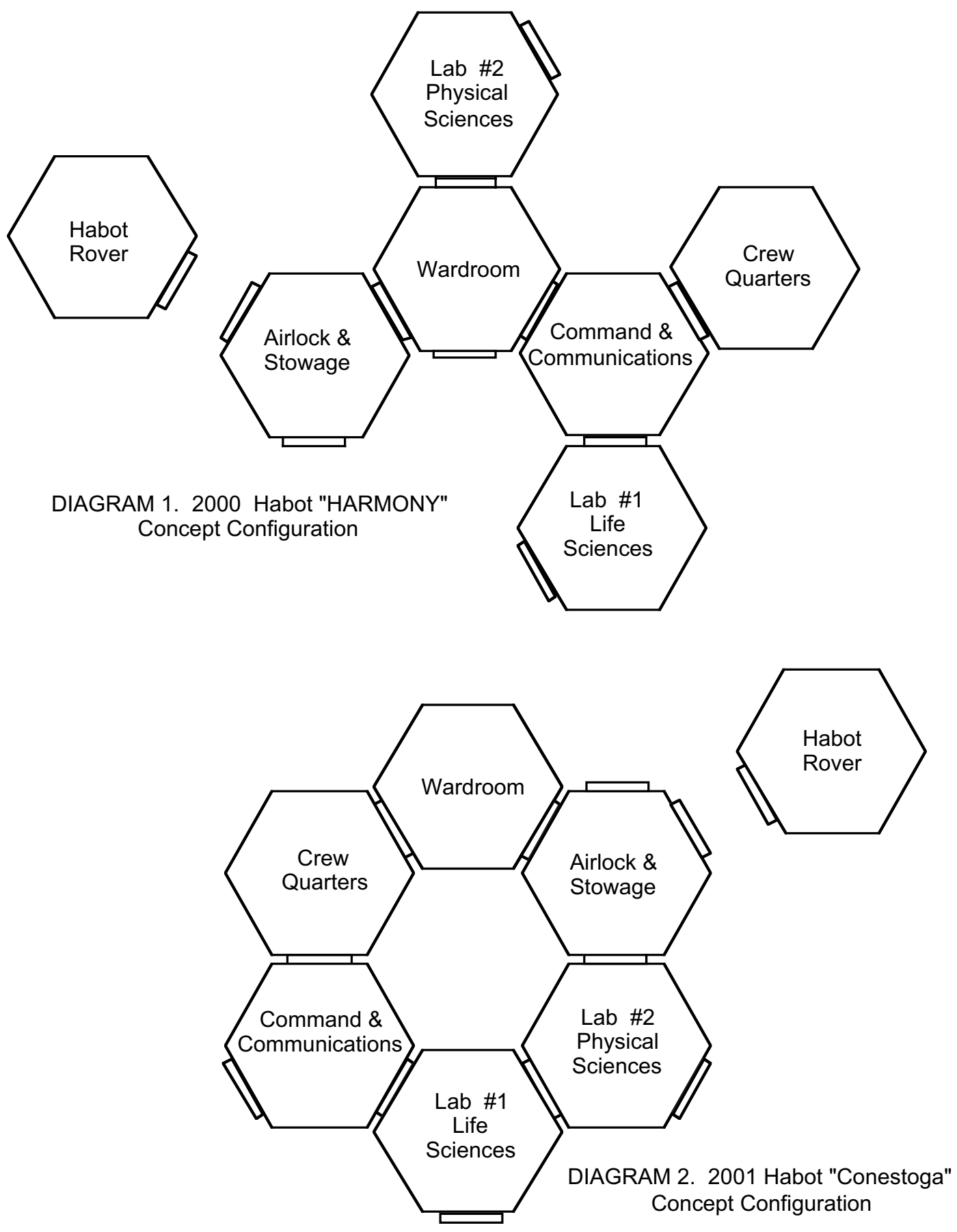


\section{ARCHITECTURAL ASSUMPTIONS}

HMVDM depends upon an ensemble of architectural assumptions, some of which are explicit and some of which are more subtle and implicit. The means of conveying these assumptions are a series of diagrams and sketches.

The medium for conveying the three dimensional architectural assumptions is a series of freehand sketches from the author's notebook. These sketches are intended to convey the main ideas as simply as possible. The sketches help to avoid the frequent error of using CAD drawings or models to present preliminary ideas - the error of being overly precise. These sketches allow the portrayal of the architectural assumptions without giving the appearance of commitment to a particular design.

DIAGRAM 1 and DIAGRAM 2 present John Mankin's early configuration concepts for the Habot mobile base clusters $(2000,2001)$. In both these clusters, there are node units with at least three ports. Some have more ports - up to four or five. In DIAGRAM1, some modules have one or two ports. The hexagonal plan geometry is expressive of the scheme for combining Habots formally, however, as pressure vessels, these hexagonal prisms are unrealistic and impractical.

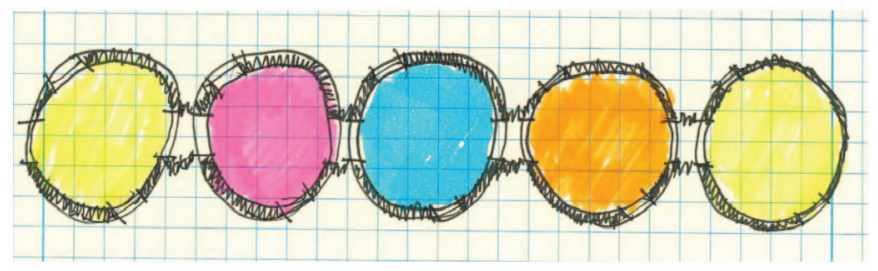

DIAGRAM 3. Linear cluster of cylindrical modules.

DIAGRAM 3 shows the simplest configuration for a Habot configuration, a linear arrangement. The Habot modules appear as circular plan to represent cylindrical volumes. In this linear configuration, each module has two main pressure ports, on axis, $180^{\circ}$ apart. This sketch suggests some windows at $60^{\circ}$ from the adjacent pressure port hatch.

SKETCHES $1 \mathrm{a}$ and $1 \mathrm{~b}$ illustrate a concept for the floor plans of an Excursion Habot. SKETCH 1a shows the upper floor plan, with the suggestion of two private sleep compartments and some dense-pack stowage. At the north window position, it shows a driver's seat. SKETCH $1 \mathrm{~b}$ shows the lower floor plan, with the single pressure port at the north position, and a driver's seat in the south window position, oriented in the opposite direction from the upper level driver's seat. The dense packing of equipment appears on the east and west sides of the lower level. SKETCH $1 \mathrm{~b}$ also portrays the mobility system as four large wheels, on a wide wheelbase.

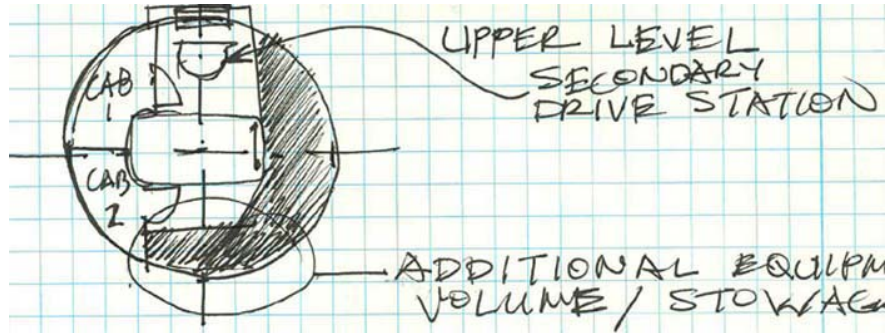

SKETCH 1a. Upper level floor plan of an Excursion Habot

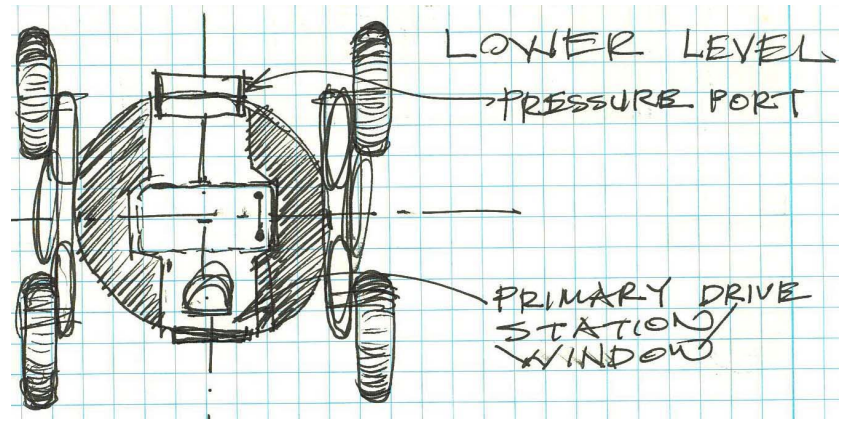

SKETCH 1b. Lower level floor plan of an Excursion Habot.

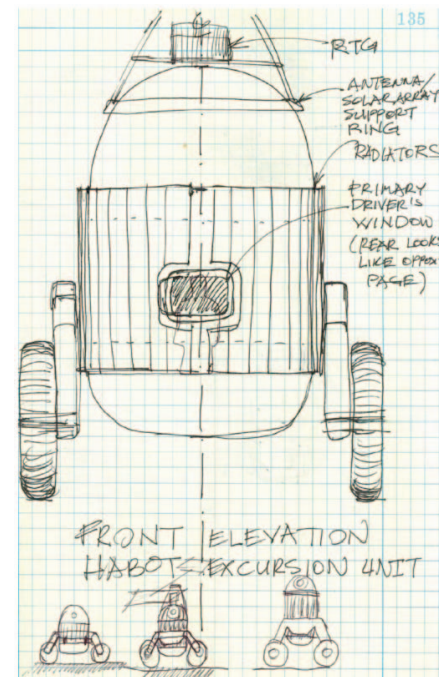

SKETCH 2a. "Front" elevation of Excursion Habot.

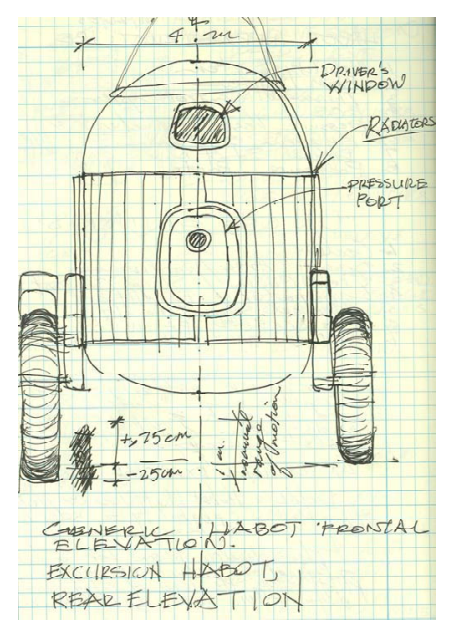

SKETCH 2b. "Back" elevation of Excursion Habot.
SKETCH 2a presents an exterior view of the "front" of the Excursion Habot. The driver's window is set low to the wheelbase, such that the top of the "rocker-boogie" mechanism reaches the height of the window centerline. An outline of the driver's body position appears in the window and through the wall.

SKETCH $2 b$ shows the "back" elevation of the Excursion Habot. The pressure port hatch appears as the main feature in this view. Above the hatch is the secondary driver's station, behind the window in the upper dome. 
In this concept, the upper and lower end domes of the pressure vessel are different degrees of ellipse. The lower end dome is a shallow, oblate ellipse. The upper end dome is approximately a hemisphere. This dichotomy of dome geometry does not carry over into the HMVDM, which treats end domes as being equal.

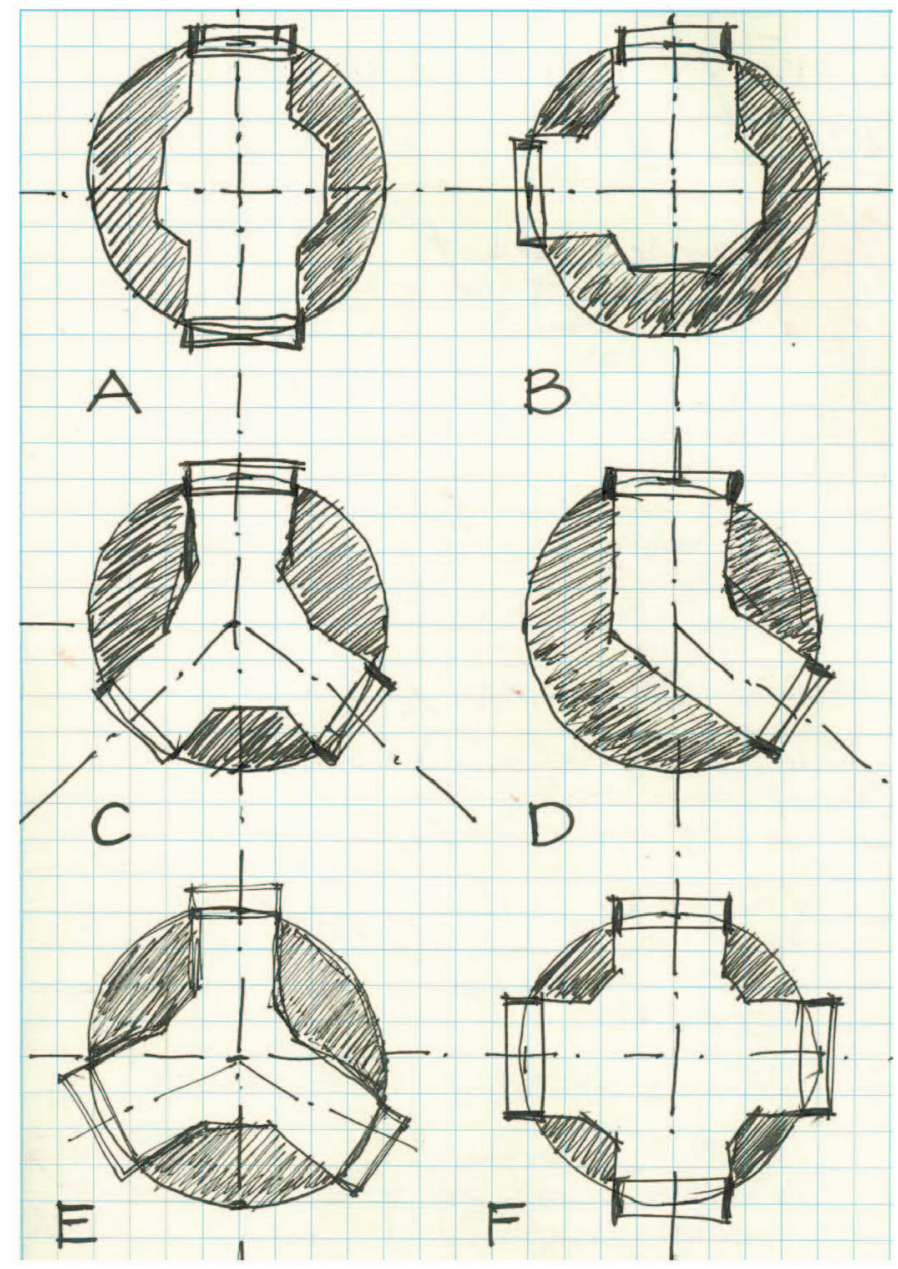

SKETCH 3. Poché study of Habot lower level floor plans.

This set of four sketches just begins to explore the potential richness and complexity of the Habot floor plans. SKETCH 3 presents six pochéd plan options for the Habot lower floor. SKETCH $3 A$ recapitulates the axial two-port plan from SKETCH 1b. 3B shows a plan with two ports at $90^{\circ}$ apart. $3 \mathrm{D}$ shows two ports at $120^{\circ}$ degrees separation. The most interesting aspect of comparing $3 \mathrm{~A}, 3 \mathrm{~B}$, and $3 \mathrm{D}$ is what happens to the pochéd equipment and stowage areas and volumes. In $3 \mathrm{~A}$, the solid area is symmetrical. In $3 \mathrm{~B}$ and $3 \mathrm{D}$, there is one more extensive "wrap" of equipment around the inside of the cylinder, concurrent with a much smaller solid area in the narrower angle. SKETCHES $3 \mathrm{C}$ and $3 \mathrm{E}$ illustrate a three-port floor plan. 3E shows $a 120^{\circ}$ plan, symmetric about three axes, with three solid poché areas of equal size between each of the three ports. $3 \mathrm{C}$ shows a plan that is symmetric about only one axis, from north to south, with two ports at $60^{\circ}$ at the south end. This difference may appear subtle at first, but it portends significant differences not only in how the interior area is divided into equal versus unequal segments, and in the possibilities for linking up Habot modules. Finally, SKETCH 3F shows a four-port, two-axis lower floor plan. The distinctive feature of this floor plan, especially compared to $3 \mathrm{~A}$, is how little area is available for equipment and stowage accommodations. The pochéd areas are the smallest of all six plans.

What the SKETCH 3 analysis shows is that the more pressure ports and circulation area to access those ports- the less area and volume is available to accommodate equipment. The two-port plan may prove quite tight, but the four-port plan is almost certainly unrealistic as a functional work area. Such an arrangement would be useful only as a circulation node. The three-port options fall in between these two extremes. To determine how useful the equipment and stowage volumes would be requires further analysis. In the two port plan $3 \mathrm{~A}$, it is possible to recess the equipment surface away from the circulation path at the center, thus creating more of a dedicated work environment or workstation. Such a focused or dedicated arrangement is much more difficult to accomplish in the three and four port plans because of the fact that they are so completely in the circulation path.

SKETCHES $4 \mathrm{a}$ and $4 \mathrm{~b}$ present conceptual floor plans for the Habot. The various functional areas appear shaded in colors. Continuing with the lower floor theme of SKETCH 3, the lower level appears in SKETCH 4b. 4b follows the contoured equipment installation and stowage arrangement from SKETCH $1 \mathrm{~b}$ and SKETCH $3 a$. In the $4 \mathrm{~b}$ representation, this equipment and stowage volume is differentiated into a galley, food storage and "wardroom table" on the left side and a personal hygiene facility, life support rack and off-axis driver's station. The ship ladder to the upper floor appears right of the centerline, where it ascends from near the center of the lower level to the upper level.

SKETCH 4a shows where the ship ladder arrives at the upper floor. There is a short landing at the top. A crewmember climbing this ladder must choose to turn left or right toward one of the private crew cabins. The proportion of the areas of these crew cabins and personal stowage may seem quite large, but relative to the module size of $4 \mathrm{~m}$ in diameter, they are actually quite modest. 


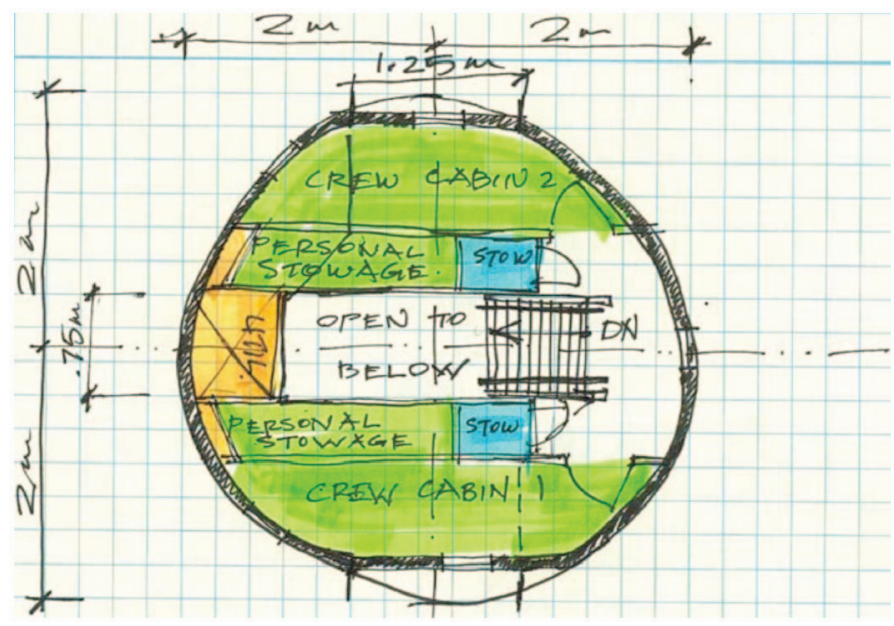

SKETCH 4a. Habot base module, upper level floor plan.

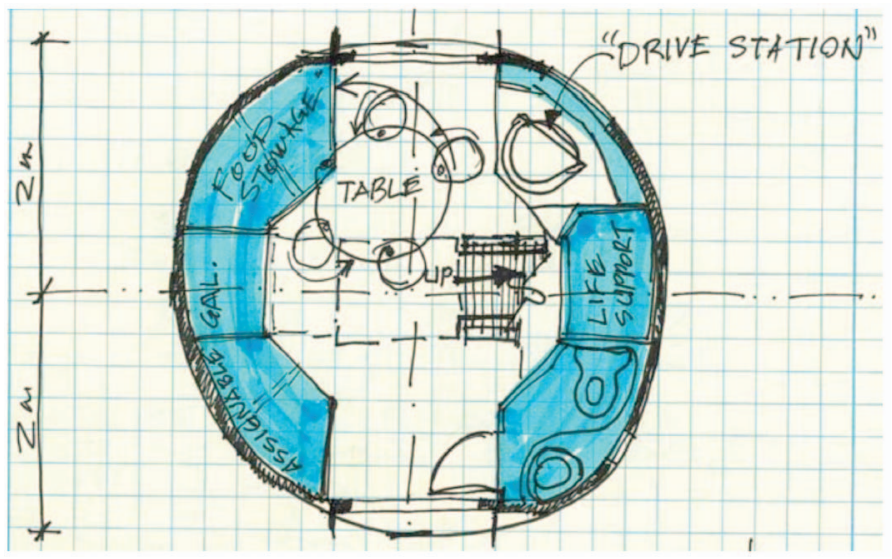

SKETCH 4b. Habot base module, lower level floor plan.

SKETCHES $5 \mathrm{a}$ and $5 \mathrm{~b}$ present "building sections" through a Habot module. In these sections, the floor assemblies appear as simple truss structures about $0.5 \mathrm{~m}$ high. They are shaded to suggest the solidity of these floor decks. Within this floor height, there would be sufficient volume to install equipment and accommodate a variety of stowage.

5 a shows the "transverse" building section with the ship ladder ascending at about a $70^{\circ}$ angle from the "bilge" below the lower floor deck to the upper floor. In the background, the interior side of a pressure port hatch appears, with its hinge side indicated by the dashed angle line. One of the crew cabin doors appears above, at the top of the ship ladder. The back clearance shown on this sketch is almost certainly inadequate. In the HMVDM, the minimum value for vertical core back clearance is $1.5 \mathrm{~m}$.

$5 \mathrm{~b}$ shows the "longitudinal" building section, referring to the "long axis" from pressure port to pressure port on opposite sides of the module. These pressure ports appear on the left and right sides of the lower level floor.
The building section is cut along the long axis, looking toward the ship ladder, showing the treads or rungs as it ascends from below the lower floor deck to the upper floor. The crew cabin doors appear on the left and right sides of the ship ladder, viewed from inside the crew cabins.

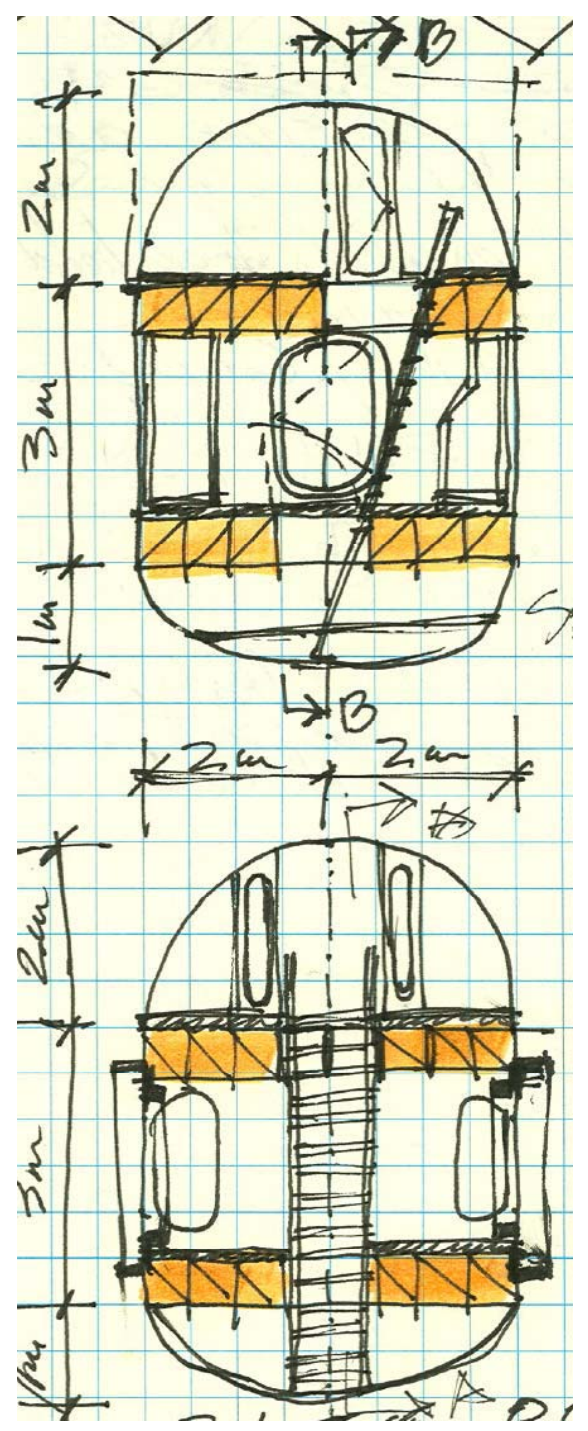

SKETCH 5a. (Above) Transverse Building Section and SKETCH 5b. (Below) Longitudinal Building Section, view to the ship ladder.

SKETCH 6 shows a more detailed view of a longitudinal building section, however, it looks in the opposite direction of $5 b$ - away from the ship ladder. Indeed, the viewer could be on the ship ladder, descending "sailor style" with the back to the treads. A particular feature of SKETCH 6 is the window that appears in the center wall of the lower level. This window occupies the on-center position that counts as a pressure port location in the constant value for number of pressure ports. 


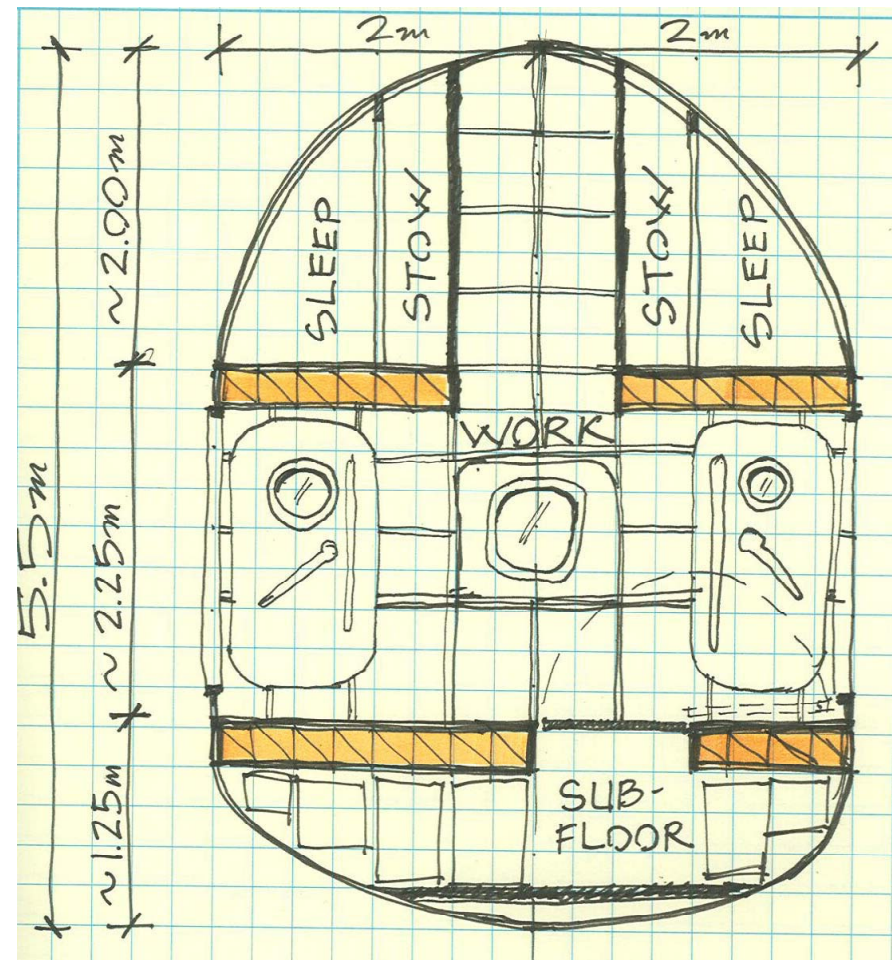

SKETCH 6. Longitudinal Building Section of Habot, view from the ship ladder.

them -- in a few respects. The floor assembly heights are not as great - only about $0.25 \mathrm{~m}$ instead of $0.50 \mathrm{~m}$. This shallower floor height would mean that the floors could accommodate conduits, ductwork, and plumbing, but probably not much equipment or stowage. In this respect, the height of the floors in SKETCH 6 are more like conventional Earth residential floor construction as opposed to $5 \mathrm{a}$ and $5 \mathrm{~b}$ which are more like Earth industrial/ commercial construction. The "back wall" in SKETCH 6 shows a system of panels, uprights, and stringers to accommodate equipment installation and stowage compartments. The subfloor area under the lower floor is also different. In $5 b$, the access is placed symmetrically in line with the ship ladder. In SKETCH 6, the access hatch is off center - not only to the left of the ship ladder centerline, but also off center from the long axis. This arrangement affords more flexibility in not requiring that the penetrations in both floor decks both align along the one vertical circulation core. The total volume penalty of the vertical core is not much affected.

SKETCH 7 presents a view of how the habitat would integrate with some of the other Habot systems. It shows a "girdle" of thermally conductive carbon radiators. These radiators have plumbing connections to pass coolant to them from the area near the pressure port. The pressure port hatch shows a concept for structural stiffening, with a small window. Around the top of the dome is a superstructure to support three separate but connected energy systems. Mounted on the sides of this structure are photovoltaic cells such as appear in FIGURE 1 as the blue towers on the top of the hexagonal Habots. In SKETCH 7, the photovoltaic cells would cover a much larger area than the thin poles of FIGURE 1. Mounted on top of the dome is a radio thermal generator (RTG) that provides back-up power to the Habot, especially during the lunar night when the solar arrays would be of no use. The RTG would also provide supplementary power during the lunar day, when the crew and Habot robotic systems are likely to become more active. Mounted on a pyramidal truss at the top of the superstructure appears a parabolic receiving antenna to receive beamed microwave or laser power. This power could be beamed from a solar power satellite system (SPSS) at an Earth-Moon libration point or from a nuclear reactor on the lunar surface (Williams, et al, 1993, p 1920; Cohen, 2004, p 6-7).

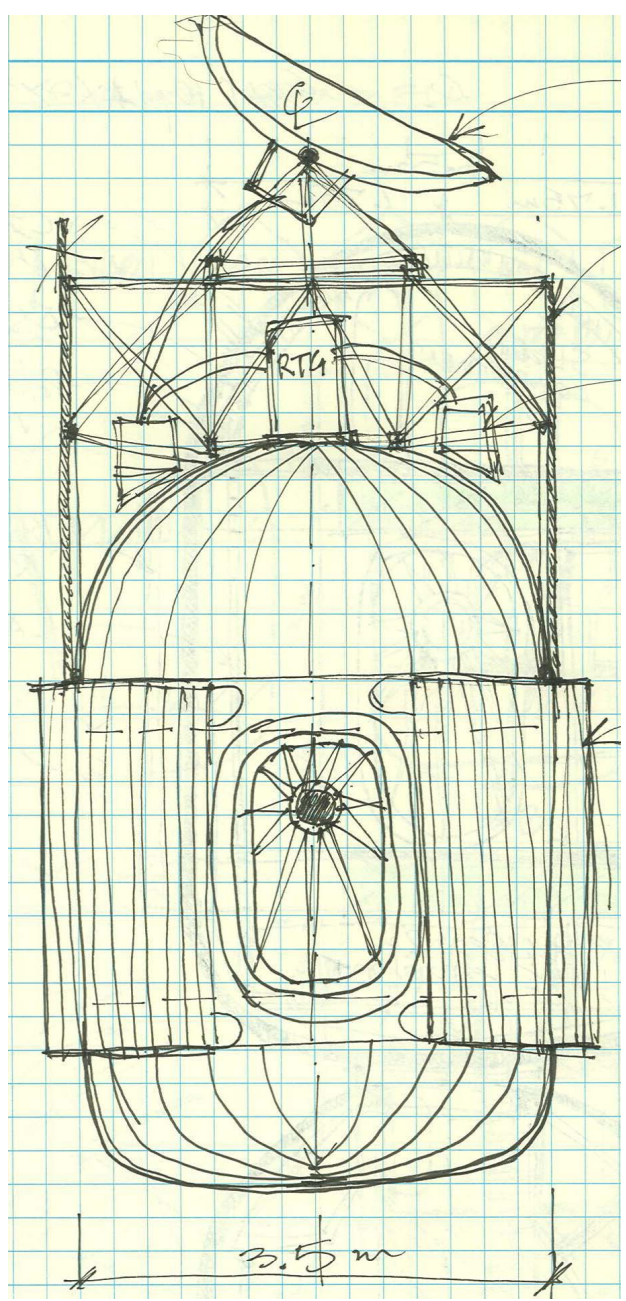

SKETCH 7. Elevation of Habot Exterior with a partial section of the energy systems mounted on the upper dome. 


\section{LOGIC ASSUMPTIONS}

In developing this HMVDM for this pilot study, the methodology began from several logical assumptions:

\section{CONSTANT VOLUME:}

The model affords one value for total volume that provides a constant for the model.

\section{SINGLE PRESSURE VESSEL HABITAT CORE:}

This analysis will address a single pressurized module. The possibility that there may be advantages to distributing the crew accommodations and other equipment to more than one module is a completely separate question, outside the scope of the pilot study.

\section{VERTICAL CYLINDER:}

To provide the requisite volume, the Habot will employ a squat vertical cylinder, the proverbial "tuna can" type module.

3a. End Dome -- The end closure on the cylinder will be an ellipsoidal dome, the most efficient shape for closing the pressure gradient at the end of a cylinder. There will be no pressure penetrations in the ellipsoidal domes.

$\underline{3 b .}$ Pressure Ports -- All pressure wall penetrations will occur in the cylindrical side, using a single standard pressure port that will be compatible with EVA airlocks, rover docking port, inflatables connection port, sample airlock, etc.

\section{DUAL, REMOTE EGRESS AND CIRCULATION:}

To ensure fire safety and successful evacuation, each pressurized volume must provide dual remote egress to the other pressurized volumes in a Habot cluster. This assumption follows the basic rule of fire safety in occupancies on earth.

4a. Vertical Circulation -- The vertical circulation system shall be a stair ladder of approximately $62.5^{\circ}$ slope, in conformance with NFPA 101 standard for stair ladders. The great majority of users will be technicians on the Earth. Subsequent studies may suggest a different design or slope for the Moon.

4b. Vertical Circulation Volume - Assuming a stair width of $1 \mathrm{~m}$, including handrails, the vertical circulation zone would extend vertically from deck to deck: $1 \mathrm{~m}$ wide $\mathrm{x}$ $2.5 \mathrm{~m}$ vertical run $\mathrm{x}$ deck-to-deck height rise. This volumetric penalty applies regardless of diameter or total volume.

\section{INTERSTITIAL EQUIPMENT \& STOWAGE DECKS}

HMVDM postulates an interstitial equipment deck between the primary living and working level decks. This assumption locates fixed equipment, including batteries, power systems, life support systems, EVA pumping, parts and spares stowage, dry food storage, freezers, clothes washing and drying, etc. within or below decks.

\section{FLOOR TO CEILING HEIGHTS:}

The nominal clear floor to ceiling height in the living and working areas is the floor deck to floor deck height, minus the interstitial depth. Floor to floor height and number of floor decks are input values to the preferred criteria range. The sketches show a hemispherical dome, taller than the lower dome, but in fact, the HMVDM treats the domes as identical.

6a. The upper dome -- will remain largely unobstructed to provide a large volume and sense of height on top of a living area. Thus, the upper deck utility chase may be under the floor.

6b. The lower dome (the "bilge") -- will be below an interstitial equipment deck, so a bilge deck below will limit its complete height. Given an ellipsoidal aspect ratio as in input preferred criteria, the height and volume of the domes will vary directly with the radius of the Habitat cylinder.

6c. The working (lab) deck - The working level is assumed to be on the lower floor or deck. It may have utility plenums within or below the floor deck.

\section{DEFINED VALUES WITHIN THE MODEL}

The model provides precise Excel definitions for the variables, constants, preferred constraint criteria, and derived values.

\section{CONSTRAINT CRITERIA}

The constraint criteria include two types of values, Constants and Constraint Values. These values appear in the control array that runs across the bottom of the HMVDM spreadsheet.

The two most important of these criteria are Constant Volume, a real number, which appears in the upper left box, and the number of pressure ports, an integer, in the box to the right. The "headline" banner at the top of the spreadsheet repeats the constant volume constraint. The other criteria define the value ranges that control the limits for the dependent variables. The definitions for constraint criteria follow. In some cases, these definitions include an initial default value, which the user can change by entering a different number in the control array. The constraint criteria cover five main topics: 
height and volume, end domes, vertical circulation, floor decks, and pressure ports.

\section{HEIGHT AND VOLUME}

Height and volume is the topic under which the constant volume applies most directly. It encompasses the height of the "tuna can" cylinder. The volume in the top and bottom end domes is also relevant, but is treated as a separate topic.

Constant Volume -- Volume.Const: Enter the volume in $\mathrm{m}^{3}$ for which the spreadsheet analyzes the geometric $\&$ volumetric properties of the Habitat pressure vessel. This value repeats in the top line. The typical range is 50 to $200 \mathrm{~m}^{3}$. The initial value is $50 \mathrm{~m}^{3}$.

Cylinder Minimum Height Cyl.Min.Ht: Enter the minimum desired height for the straight cylinder equivalent volume in meters. The typical range is $\sim 2 \mathrm{~m}$ to $6 \mathrm{~m}$.

Cylinder Maximum Height Cyl.Max.Ht: This criterion provides an upward sanity check on the allowable height of the habitat module. It assumes that the entire volume would be cylindrical. Enter the maximum allowable value in meters. The range is from $\sim 3 \mathrm{~m}$ to $\sim 8 \mathrm{~m}$. The initial value is $3.5 \mathrm{~m}$.

\section{END DOMES}

The end domes carry the potential to be the greatest wild card in total allocation of volume. They can range from 0 percent to 100 percent of the total volume.

Ratio of Dome Height to Diameter Ratio.Dom.Ht Dia: Enter the ratio of the height of the ellipsoidal end dome to the diameter of the Habitat cylinder. The typical range is from 0.1 for a fairly flat end dome to 0.5 for a hemispherical end dome. The initial ratio is .3.

End Dome Minimum Height CDomMinHt: Enter the minimum height in meters desired for the ellipsoidal end dome of the habitat pressure vessel. The range is 0 to about $3.0 \mathrm{~m}$. The initial value is $1 \mathrm{~m}$.

End Dome Maximum Height CDomMaxHt: Enter the maximum desired height in meters for the ellipsoidal end domes. The range is $.5 \mathrm{~m}$ to about $3.5 \mathrm{~m}$. The initial value is $3 \mathrm{~m}$.

End Domes Percent Volume CDomesPctVol: Enter the percentage of the total volume that should occur in the end domes. The range is $0 \%$ to $100 \%$. $0 \%$ means the end domes are perfectly flat. $100 \%$ means that the end domes contain the entire volume - as in a sphere or an ellipsoid -- and there is no straight cylindrical section.
End Domes Maximum Percent Volume CDomesMaxVol: Enter the maximum percentage (fraction of 1) volume preferred in the ellipsoidal end domes. The range is 0 to 1 , representing $0 \%$ to $100 \%$. The pilot model assumes that the two end domes are equal in volume, which implies equal height. However, there is no actual requirement for the domes to be identical, as shown in some of the preceding sketches.

\section{PRESSURE PORTS}

Pressure ports drive the circumference of the habitat, directly increasing or decreasing the radius. Changes in the radius affect the floor area, $\mathrm{A}$, and total volume by the familiar exponential expression:

$A=\pi r^{2}$

In habitat module with a design requirement for a great many pressure ports or penetrations spaced apart may act as the determining factor in sizing the habitat. As this pilot project evolved, the number of ports construct expanded to include all penetrations through the primary pressure vessel structure, notably windows, EVA airlock port, and sample airlock port.

Minimum Number of Ports MinNumPorts: Enter a whole number (integer) for the desired minimum number of radial pressure ports. The typical range is from 2 to 8 . The initial value is 4 .

Pressure Ports On-Center Spacing PressPort.o.C: Enter the desired minimal on-center spacing of radial pressure ports. The approach to selecting this value is to specify a clearance distance to accommodate docking of multiple Habots, pressurized rovers or Excursion Habots, external airlocks, or inflatable modules, etc.

\section{FLOORS}

Floors have two principal characteristics as constraint criteria. First, a floor has area, which, when multiplied by a clear height yields a volume that can be used for functional activities. The default setting for clear volume height is $2 \mathrm{~m}$. Second, there can be more than one floor, which introduces the floor-to-floor height, measured from top of floor to top of floor as. Finally, the floor construction involves the floor section thickness.

Minimum Floor Area FL.AreaMin: Enter the minimum floor area in sq. meters desired for a single floor deck. The range is from $\sim 10$ to $\sim 100 \mathrm{~m}^{2}$.

Maximum Floor Area FL.AreaMax: Enter the maximum desired or allowable floor area for a single floor in $\mathrm{m}^{2}$. The range is about 20 to $120 \mathrm{~m}^{2}$. 
Number of Floor Decks NumFL.Decks: Enter the number of floor decks desired in the habitat. This value is neither a minima nor a maxima because it derives from actual target design concepts. The typical range is from 1 to 3 decks. The value reflects the number of decks, where there is a quarter-height, interstitial space between two full-height decks. Enter a new value for each change in floor deck design, with interstitial spaces as decimal fractions.

Maximum Number of Floors MaxNum.Fl.Asslys: Enter the maximum number of floor deck assemblies as an integer. This value indicates the maximum allowable floor decks should the Vol.Const require more than NumFL.Decks for complete accommodation. The initial value is 2 floor decks, based upon the typical "tuna can" floor deck configuration.

Floor-to-Floor Height FL.Deck.HT: Enter the floor deck height, measured as a top of floor to top of floor height in meters. In the top end dome, measure the floor deck height from the top of structural floor to the underside of the ceiling or deck above. In the lower dome, measure from the top of the low point of the shell to the top of the structural floor deck above. The range is 2 to 3.5 meters.

\section{VERTICAL CIRCULATION}

Vertical circulation constitutes an overhead cost in terms of usable volume. Because the size of a ship ladder or other vertical movement device and the clearances around it is fixed based on anthropometric size, it is largely independent of the preceding volume and dimensional sizing factors. In a small habitat with multiple floor decks, the vertical circulation core can occupy a significant portion of the total volume.

Number of Vertical Circulation Cores Num.Vert.Circ.Cores: Enter the number of vertical circulation cores in a single habitat pressure vessel as an integer. The range is the integers 1 and 2 . The initial value is one, as the minimum value in a multi-floor habitat.

Vertical Core Width Vert.Width: Enter the value in meters for the total width of the vertical circulation core, typically a stair ladder at $60^{\circ}$ to $70^{\circ}$ angle from the deck. The range is from $\sim 0.5 \mathrm{~m}$ to $\sim 1.5 \mathrm{~m}$. The initial value is $1.25 \mathrm{~m}$, the dimension of the square Space Station Freedom hatches. With two handrails having a side clearance of $7.5 \mathrm{~cm}$ each, the net clear passage is $1.1 \mathrm{~m}$, allowing the crew to move a $\sim 1 \mathrm{~m}$ wide object without crushing their hands or arms.

Vertical Core Back Clearance Vert.Back.Clr: Enter the depth in meters of the back clearance from the stairladder front surface. This measure indicates consideration of the top, intermediate and bottom landing in a straight stair design (no scissors flights).
Generally, the landing must approximate a square with sides equal to the width, "Vert.Width" plus the run of the stair slope. The typical range for a stair-ladder is from $1 \mathrm{~m}$ to $2.5 \mathrm{~m}$. The initial value is $1.5 \mathrm{~m}$, which assumes a total stair-ladder horizontal run of $0.5 \mathrm{~m}$.

Vertical Circulation Percent Volume VCircMaxPctVol: Enter the desired maximum percentage of pressurized volume to be occupied by the vertical circulation core (s). Typically, with a ship ladder at $60^{\circ}$ to $70^{\circ}$, this core will occupy $\sim 1.5 \mathrm{~m}^{3}$ for each meter of height. Measure from the top of the bottom floor to the top of the uppermost floor. The initial value is $5 \%$. Although some designs use very small vertical ladder-ways, it is essential to establish a minimum value for a stair-ladder that will meet the Life Safety Code, both on the Moon and in the manufacturing facility on Earth.

\section{KEY NUMERICAL EXPRESSIONS}

The Pilot Study HMVDM builds upon the defined constraint criteria to assign values to the key numerical factors. These arithmetic expressions serve as the building blocks for the programming logic in the Dependent Variable Evaluation arguments.

\section{VOLUMETRICS}

As in the constraint criteria, above, the measurements include height and volume for the cylinder dimensions.

Constant Volume in m3 Volume.Const -- Each analysis in terms of setting up the spreadsheet analysis requires the entry of a single value for constant volume. This value acts as a constant.

\section{$=$ Volume.Const}

Cylinder Diameter in $\mathrm{m}$-- is the major independent variable that the HMVDM is evaluating.

$=$ Cyl.Dia

Cylinder Circumference in m CylCircumf -- A covariant of the cylinder diameter, given in the Excel macro:

$$
=\mathrm{PI}()^{\star} \text { Cyl.Dia }
$$

Height of an Equivalent Straight Cylinder of the full volume in $\mathrm{m} \mathrm{Ht.Str.Cyl.}$

\section{$=$ Volume.Const $/$ Cyl.Cross.Sec.Vol}

Cylindrical Cross Sectional Volume Cyl.Cross.Sec.Vol -$1 \mathrm{~m}$ high slice in $\mathrm{m}^{2}$ (Equals Floor Area in $\mathrm{m}^{2}$ ).

$=\mathrm{PI}()^{\star}($ Cyl.Dia/2)*(Cyl.Dia/2) 


\section{END DOMES}

The end domes are the second-order repositories of volume. This section

Number of Pressure Ports at_? $m$ on center num.press.ports -- This macro finds the number of pressure ports that fit the circumference at a given spacing on center. The test value is 4.5 meters, which reflects a value slightly larger than a Space Station Freedom Module to allow sufficient clearance for inflatables (greenhouses) and rover ports. It assumes equal spacing between pressure ports around the circumference. The sizing macro is:

$=$ Cyl.Circumf/PressPort.o.c.

Height of Ellipsoidal Dome in $\mathrm{m}^{3}$ Ht.Ellips.Dome -

$=$ Ratio.Dom.Ht_Dia*Cyl.Dia

Approximate Volume of 1 Ellipsoidal Dome in $\mathrm{m}^{3}$ vol.ellips.dome -

$=\mathrm{PI}()^{\star}$ Cyl.Dia ${ }^{\star}$ Cyl.Dia*Ht.Ellips.Dome/6

Two Domes as a Percentage of the Equivalent Straight Cylindrical Volume (no variable) --

$=2^{*}$ Vol.Ellips.Dome/Volume.Const

\section{FLOORS}

Although it might seem that floors would occur in whole number integers, by treating them as a real number, it is possible to assess the value range

Number of Floor Deck Assemblies num.fl.asslys -Based upon the computed height needed to provide the volume, it is possible to estimate the number of dual deck assemblies that fit into that volume and how efficiently they can make use of it, given all the foregoing assumptions. Also, by rounding, the arithmetic expression is adjusted to the degree of precision in the model.

\section{$=$ ROUND(Ht.Str.Cyl/FL.Deck.HT,2)}

\section{VERTICAL CIRCULATION}

The vertical circulation expressions calculate the actual volume invested in the vertical core or cores.

Total Volume of the Vertical Circulation System in $\mathrm{m}^{3}$ Vcirc.vol --

$=$ Num.FI.Asslys*FL.Deck.HT*

Num.Vert.Circ.Cores ${ }^{*}$ Vert.Back.ClrVert.Width

Vertical Circulation as a Percentage of Total VolumeVcircPctVol -

$=$ VCircVol/Volume.Const

\section{DEPENDENT VARIABLE EVALUATION CRITERIA}

The main tools of this study are the seven evaluation criteria macros. The macro code for each criterion appears in each cell of the column below the respective title in the spreadsheet title row. These macros read the values residing in the named variables of the control array at the bottom of the spreadsheet. Many of the specific algorithms are written with rounding and ceiling functions to provide estimates rather than hard number determinations for the preferred criteria. For this reason, in some cases, the preferred data range indicated for dependent variables will extend one or two cells vertically above or below a strict construction of the criteria. This approach is more consistent with the precision of all the calculations and factors involved in generating the constants and input criteria values.

C 1 Number of Pressure Ports: This criterion evaluates the number of pressure ports it is possible to place around the circumference of the habitat. The number of radial ports is a critical issue for habitat architectures that may require a large number of ports. Some unconnected or stand-alone habitats may require from six to eight ports. The evaluation criteria macro, $C_{-} 1$ is:

$=\mathrm{IF}($ ROUND(Num.Press.Ports,0)>=MinNumPorts, "<<<"," ") 
C 2 Floor Deck Area: This criterion evaluates the floor area of a single floor deck in the habitat. Floor area per floor deck is a key determinant in how useful and efficient an architectural floor plan can be. Generally, larger floor plans offer greater flexibility and utility. However, the diameter constrains this floor area significantly. The evaluation criteria macro, C_2 is:

$$
\begin{aligned}
& =I F(A N D(C E I L I N G(C y l . C r o s s . S e c . V o l, 10)>=F L . A r e a M i n, F L O O R(C y l . C r o s s . S e c . V o l, 10) \\
& <=F L . A r e a M a x), "<<<", " ~ ")
\end{aligned}
$$

C 3 Height of Ellipsoidal End Dome: This criterion evaluates the height of the ellipsoidal end dome. There are essentially two strategies for the design of end domes. The evaluation criteria macro, $\mathbf{C} \_\mathbf{3}$ is:

$$
\begin{aligned}
& =\operatorname{IF}(\text { AND }(\text { ROUND(Ht.Ellips.Dome,1)>=CDomMinHt,ROUND(Ht.Ellips.Dome, } 1) \\
& >=\text { CDomMaxHt), } "<<<", " ~ ")
\end{aligned}
$$

C 4 Equivalent Full Volume: This criterion evaluates the height of the equivalent full volume as if the ellipsoidal domes were perfectly flat. The reason for neglecting the curvature of the domes is to have a consistent basis for comparison. Thus, this criterion evaluates an abstracted, equivalent cylindrical volume, which is slightly shorter than the corresponding habitat with end domes. The evaluation criteria macro, $\mathbf{C} \_4$ is:

$$
=\operatorname{IF}(\text { AND }(R O U N D(H t . S t r . C y l, 0)<=C y l . M a x . H t, H t . S t r . C y l>=R O U N D(C y l . M i n . H t, 1)), " \ll<" \text {," ") }
$$

C 5 Domes Percentage of Total Volume: This criterion evaluates the combined valued of two ellipsoidal end domes as a percentage of the total constant volume. The evaluation criteria macro, $\mathbf{C} \_\mathbf{5}$ is:

$=\mathrm{IF}(\mathrm{CDomesPctVol}>=0.1$,

IF(AND(FLOOR(CDomesPctVol,0.1)<=CDomesMaxVol,CEILING(CDomesPctVol,0.1)

$>=$ CDomesVol),"<<<"," "),

\section{IF(AND(FLOOR(CDomesPctVol,0.01)<=CDomesMaxVol,CEILING}

$$
\text { (CDomesPctVol,0.01)>=CDomesVol),"<<<"," ")) }
$$

C 6 Number of Floor Decks: This criterion evaluates the number of floor decks achievable and appropriate within the habitat design and volume allocations. Generally, the floor decks occur in substantial increments that comprise a large step functions. The input number of floor decks may be a whole number (integer) or a decimal fraction to represent a partial height equipment deck. The evaluation criteria macro, $\mathbf{C} \_6$ is:

$$
\begin{aligned}
& =I F(\text { AND(ROUND(Num.FI.Asslys, 1)<=MaxNum.FI.Asslys,ROUND(Num.FI.Asslys, } 1) \\
& >=\text { NumFL.Decks),"<<<"," ") }
\end{aligned}
$$

C 7 Vertical Circulation Volume: This criterion evaluates the percentage of total volume that the vertical circulation system occupies. This derived value exhibited the greatest degree of variation among all the design concepts. To create a standard basis of comparison, this analysis replaces all the idiosyncratic designs with a common envelope for a vertical stair-ladder. The evaluation criteria macro, $\mathbf{C} \_\mathbf{7}$ is:

$$
\text { =IF(FLOOR(VCircPctVol,0.01)<=VCircMaxPctVol,"<<<"," ") }
$$




\section{FINDINGS}

The model yields a range of values for the independent variable. The preferred of best value is indicated by all seven of the " $<<$ " graphical indicators lining up. For ease of interpretation, to this alignment the author added bright yellow shading for the best alignment, and pale yellow shading for the outer values that come close to the alignment.

\section{$100 \mathrm{~m}^{3}$ CONSTANT VOLUME}

For the $100 \mathrm{~m}^{3}$ habitat, no value for the diameter satisfied all the dependent variables. The $4.75 \mathrm{~m}$ and $5.00 \mathrm{~m}$ diameters fulfilled six of the seven criteria. This result shows that a single "perfect" or complete solution that fits all the dependent variables may not exist. However, this failure to find a solution provides valuable insight: the bounding of the "trade space" and what are the important "trade-offs."

In this case, the $4.75 \mathrm{~m}$ and $5.00 \mathrm{~m}$ diameters meet all the dependent variable evaluation criteria except for C_6, the number of floor deck assemblies. As the diameter increases, the first acceptable value of 2.06 floor decks occurs for $5.25 \mathrm{~m}$. However, a $5.25 \mathrm{~m}$ diameter puts too much volume in the end domes, giving $45.46 \%$ of total volume, where the maximum allowed by C_5 is $35 \%$. Even with rounding permissible up to $40 \%$ of volume, $5.25 \mathrm{~m}$ does not solve the problem any better than $5.00 \mathrm{~m}$.

Going to the smaller diameter of $4.5 \mathrm{~m}$ the score is still six out of seven. However, to still provide the Vol.Const value of $100 \mathrm{~m}^{3}$, the height of the cylinder must increase to $6.29 \mathrm{~m}$. This value exceeds the C_4 maximum allowable height value of $6.00 \mathrm{~m}$, even with rounding down.

Given the result that none of the values for the independent variable meet the evaluation criteria, one must suppose that the target volume of $100 \mathrm{~m}^{3}$ is too large. This assessment that $100 \mathrm{~m} 3$ is too large for one Habot module must be understood within the context of the constraint criteria entered into the HMVDM specifically for the Habot.

\section{$50 \mathrm{~m}^{3}$ CONSTANT VOLUME $\times 2$ MODULES}

Since $100 \mathrm{~m} 3$ was too large for one Habot module, the reasonable next step is to divide the total volume between two modules. Please recall that the reasons why the $100 \mathrm{~m} 3$ would not fit was not the amount of volume in any direct sense, but rather the effects of that volume upon the architectural envelope. The dependent variable evaluation criteria for which $100 \mathrm{~m} 3$ failed were the number of floor assemblies, the percentage of volume contained in the end domes, and the height of the module cylinder. Therefore, it appeared that it should be possible to accommodate the total volume and meet the evaluation criteria in two or more modules.

One approach might be to try to reduce the $100 \mathrm{~m} 3$ volume incrementally, to say $90 \mathrm{~m} 3$, and then test whether that quantity solves the problem. While such an incremental method might pose an interesting puzzle and intellectual exercise, it begs the question of what to do with the excess $10 \mathrm{~m} 3$. The Habot Mobile Base concept does not allow "fractions" of a module. All Habot units would be produced on the same assembly line to take advantage of economies of scale in reproducing the same product as identically as possible.

Therefore, the simple, straightforward approach is to divide the total volume in half, creating two modules of $50 \mathrm{~m}^{3}$ apiece. TABLE 3 presents this solution. To make it feasible in the necessarily smaller diameter range, it was necessary to change the constant value for number of pressure ports from six to four so that the circumferential on-center spacing does not skew the diameter unreasonably.

With this approach, the result for $50 \mathrm{~m} 3$ yields one diameter value, $3.75 \mathrm{~m}$, for the independent variable that fulfills all the seven evaluation criteria for the dependent variables. The $3.50 \mathrm{~m}$ and $4.00 \mathrm{~m}$ diameters come close, each fulfilling six of seven evaluation criteria. $3.5 \mathrm{~m}$ misses on C_6, the number of floor assemblies. $4.00 \mathrm{~m}$ misses on $C \_5$, percentage of total volume in the two end domes.

The findings show that it is possible to fit the total volume and all the functional elements it represents into two Habot modules. At a practical level, this outcome means that all the required functions fit. For example, on the upper level, there would be two crew compartment volumes in each module instead of four. However, for overhead functions such as the hygiene facility and the vertical circulation core must be repeated in each of the two modules.

\section{OBSERVATIONS FROM THE PILOT STUDY}

The pilot study yields a series of observations that apply to the design parameters for the Habot module in particular, and to any "tuna can" module in general. These observations concern: increasing the diameter, decreasing the diameter, increasing the height, comparison values for the diameter, the vertical circulation and the radial pressure ports.

\section{INCREASING DIAMETER}

As the diameter increases, a greater proportion of the pressurized volume occurs in the domes. Since the domes are a relatively inefficient envelope for spatial utilization, the largest domes pose a penalty, but they do 
not impact directly the primary working and living dualdeck assemblies. However, the larger ellipsoidal domes are structurally more efficient and thus lighter in weight than the equivalent volume enclosed in a cylindrical section.

\section{DECREASING DIAMETER}

As the diameter decreases, the vertical circulation systems take up an increasing percentage of the volume. The volume that they eliminate from productive use comes from the primary working and living areas, so the greater the vertical circulation volume, so the penalty from increased circulation volume impacts the efficiency of the working and living environment directly.

\section{INCREASING HEIGHT}

Meaningful increases in volume by increasing habitat height require that the increase occur in substantial increments of typically a full floor deck. The default or initial value for floor deck assemblies is $2.25 \mathrm{~m}$ high. Some habitat designs use greater heights. None use fewer heights.

\section{VERTICAL CIRCULATION VOLUME}

Vertical circulation volumes are the lease amenable to manipulation or optimization. It is not allowable to generate a module with two floor deck levels but no way for the crew to climb from one to the other. Therefore, the total investment of volume in the vertical cores must double to provide one in each module. The HMVDM does not have a mechanism to account for duplicating such a function because it is formulated to size a single module.

\section{RADIAL PORTS}

The circumference emerges as the controlling value in determining if a diameter is acceptable, given a specified perimeter spacing between windows, pressure ports, sample airlocks, etc. The spacing between these penetrations is controlled by external clearance requirements. In this light, the selection of the on-center spacing emerges as an essential design decision.

\section{DISCUSSION}

The pilot study results raise several issues about how to interpret them. These issues include the habitability metrics, generating a CAD model from the data, the precision of the model and its output, and, perhaps most important, the generalizability of the results.

\section{HABITABILITY METRICS}

This model provides specific manipulable values that the Human Factors Engineer or the Habitability designer can consult and test in developing a space habitat concept. For example it is possible to make the volume, dimensions and number of private sleep compartments any type of value in the model: a variable, constant or a preferred criteria. Given such a diverse role for each element, it should become very straightforward to evaluate the impact on all the other volumetric, dimensional, or structural considerations in the habitat. However, to make this approach work, it is necessary to be explicit about what each of the elements are and how they relate logically.

\section{GENERATING A CAD MODEL}

It is feasible to take the output values for the dependent variables in the preferred criteria range and import them into a CAD program to construct a habitat based on the HMVDM results. FIGURE 3 shows the CAD model of a habitat generated from the HMVDM spreadsheet to reflect a constant volume of $98.666 \mathrm{~m} 3$ at a diameter of $5 \mathrm{~m}$, as shown in TABLES 1 and 2. FIGURE 3 was generated manually by employing the data from the HMVDM to generate the 3D solid representation of the Habot. This exercise indicated no significant obstacles to constructing a programmable CAD model that would automatically import dimensional values from TABLE 2 and use them to construct the habitat solid model.

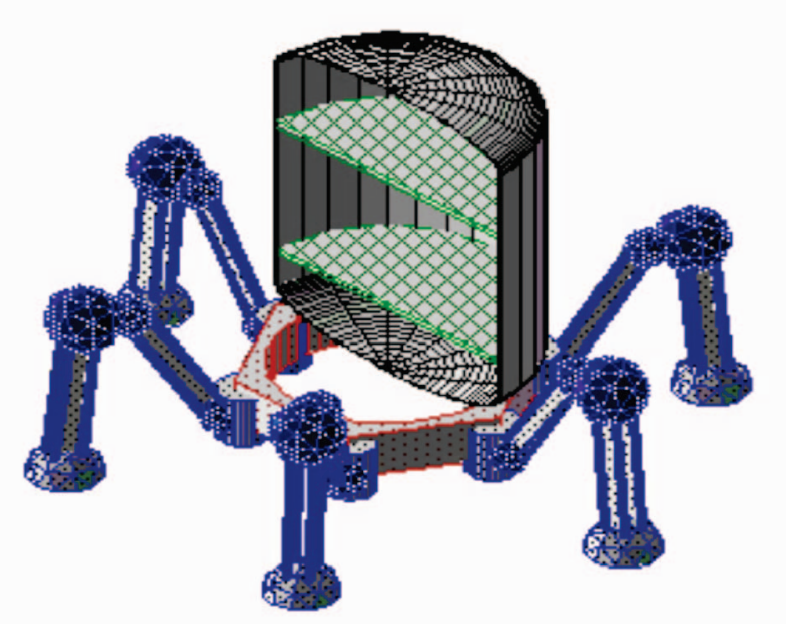

Cutaway view of $\mathrm{Habot} \mathrm{Habitat}$, with legs squatting Marc M. Cohen, Architect Ames Research Center 20030129

FIGURE 3. 3-D CAD solid model of a Habot habitat, derived from dependent variable values generated from the HMVDM pilot study. 


\section{PRECISION}

The model makes a set of assumptions about the necessary precision. The biggest assumption is that the appropriate increment for the diameter is $0.25 \mathrm{~m}$. The granularity of these increments may have a

Further development of this approach will require a better appreciation of what makes a significant increment, and a reasonable allowance for rounding. This requirement includes attention as to whether these parameters scale with the size of the habitat or whether the degree of precision remains fairly constant across a range of habitat types and sizes.

\section{VALIDITY}

There are four points of validity that arise from the HMVDM Pilot Study: selection bias, stopping rule, generalizability, and the need for validation. These questions address only the larger issues in the pilot study. There is another tier of more detailed questions about design assumptions that does not pertain to the pilot study per se or to the HMVDM methodology, but rather to the structural geometries. These questions of geometry bear further study separate from HMVDM.

Selection Bias -- The primary threat to validity is selection bias. It arises both despite and because of the effort to model a habitat. On the one hand, the constructs that make the HMVDM derive from an assessment of existing habitat concepts, but the application these existing concepts may skew the selection of important parameters. On the other hand, the effort to express these precepts as a programming abstraction pushes selection bias in the opposite direction - that the author selected certain properties largely because they were amenable to modeling in Excel as described for HMVDM.

Stopping Rule - One question that is difficult to answer is when to stop developing the model - when there is enough evaluation data. In a sense it is a quasi-legalistic discussion: is a "preponderance of the evidence" sufficient, or does the validation require "proof beyond a reasonable doubt?" For the pilot study, the particular demarcation line falls between the size and dimensions of the pressure vessel shell with the structural floor sections and the installation of volume-filling equipment and stowage. SKETCH 3 suggests that the number and spacing of circumferential pressure ports - and the clear floor areas to access them -- makes a significant inroad into the availability of solid-fillable volume on the lower floor deck. Creating an analysis of the way in which space is used to fill volumes with equipment, stowage and circulation areas will be an important next step, but it is beyond the scope of the pilot study.

Generalizability -- Generalizability is a form of validity. This Pilot Study addressed one specific module type, the
"Tuna Can" for a specific mission profile and crew size in a designated lunar environment. The way to understand the generalizability is not that it would apply to a "Tuna Can" module anywhere in the space environment (although it might), but rather that the Boolean Logic approach in the design research methodology can be constructed to serve virtually any type of geometrically describable habitat in virtually any environment or gravity regime. However, it would be necessary to construct the spreadsheet model to reflect that specific geometry and its peculiar characteristics. Further testing of this approach on completely different habitat geometries will be essential to evaluate the generalizability of the HMVDM approach.

Validation -- To make the HMVDM truly valuable and useful will require validating it against existing and historical space habitats such as Skylab, Mir, Shuttle, and ISS. This validity testing will also introduce new challenges. For example, the free volume in the Skylab Saturn Workshop, with its $6.25 \mathrm{~m}$ diameter and a total pressurized volume in the whole station of about $725 \mathrm{~m}^{3}$ for 3 crewmembers over 84 days poses a very different set of evaluation criteria than the contemporaneous Salyut 7 with about $150 \mathrm{~m} 3$ for 2 crew members over 237 days. This assessment will push the HMVDM to greater capabilities.

Assessment of Validity -- These questions of validity do not invalidate the pilot study insofar as it successfully demonstrates the design research method. The questions do point out the potential limitations of this approach as a design and planning method. In sum, these questions of validity indicate only one thing - the need for more work, more developing, more testing of the HMVDM.

\section{CONCLUSION}

This pilot study confirms that it is possible to develop abstract programming expressions from concrete architectural properties. The application of this programming logic was successful insofar as it produced findings that could determine whether a test volume was feasible as a Habot in a single habitat module.

The Habitat Multivariate Design Model pilot study demonstrates that the first phase of the design research methodology was successful. The nature of this success was to apply a Boolean logic-based approach to determining appropriate habitat dimensions for a lunar habitat, given a crew size and mission duration. The crew accommodations analysis step yielded a baseline volume for the habitat. Given this constant volume, the model found a single habitat module could not accommodate the volume and meet the requirements peculiar to the Habot. Instead, it found that dividing the total volume between two habitat modules met the evaluation criteria. 
Through this pilot study, the Habitat Multivariate Design Model achieved proof of concept, NASA Technology Readiness Level TRL-3. It succeeded in selecting a diameter as independent variable that fulfilled all the dependent variable evaluation criteria. The HMVDM Project Design Research Methodology illustrates the path to carry this study forward.

\section{ACKNOWLEDGMENTS}

I would like to thank my reviewers, Yvonne Clearwater, Andrew Gonzales, Tom Wynn, Robert Hogan, Peter Kittel, Bernadette Luna and Kurt Micheels for their help in developing and publishing this paper.

\section{REFERENCES}

Benaroya, Haym, "An Overview of Lunar Base Structures: Past and Future," AIAA 2002-6113, 1st AIAA Space Architecture Symposium (SAS 2002), Houston, Texas, USA, 10-11 October 2002. Reston, VA: AIAA.

Cohen, Marc M. (2003) "Mobile Lunar and Planetary Bases," AIAA-2003-6280, AIAA Space 2003 Conference, San Diego, CA, Sept. 23-25, 2003. Reston VA: AIAA.

Cohen, Marc M., (2004). "Mobile Lunar Base Concepts," 2004-STAIF-291, 2004 Space Technology and Applications International Forum, Albuquerque, NM, Feb. 8-11, 2004, College Park, MD: American Institute of Physics.

Cohen, Marc M., (1996) "First Mars Outpost Habitation Strategy," in Stoker, Carol and Emmart, Carter, Eds. Strategies for Mars: A Guide to Human Exploration, American Astronautical Society, Science and Technology Series, Vol. 86, San Diego, CA: Univelt, Inc. pp. 465-512.

Levri, Julie A.; Vaccari, David A.; (2002, October) "Model Implementation for Dynamic Computation of System Cost for Advanced Life Support," COSPAR, presented at the World Space Congress, Houston, TX.

Levri, Julie A., et al, (2003, Feb. 26, working draft) "Advanced Life Support Equivalent System Mass Guidelines." Moffett Field, CA: NASA-Ames Research Center.

Mankins, John C., "Modular Architecture Options for Lunar Exploration and Development," IAA.13.2.05, $51^{\text {st }}$ International Astronautical Congress, Rio de Janeiro, Brazil. October 2-6, 2000, Paris, France: IAA.

Mankins, John C. (2001) "Modular Architecture Options for Lunar Exploration and Development," Space Technology, Vol. 21, pp. 53-64.

Williams, M. D., De Young, R. J., Schuster, G. L., Choi, S. H., Dagle, J. E., Coomes, E. P., Antoniak, Z. I.,
Bamberger, J. A., Bates, J. M., Chiu, M. A., Dodge, R. E., and Wise, J. A. (1993) Power Transmission by Laser Beam from Lunar-Synchronous Satellite, NASA TM 4496, Washington DC, NASA.

\section{CONTACT}

Marc M. Cohen, Arch.D, Architect

Advanced Projects Branch

Mail Stop 244-14

NASA-Ames Research Center

Moffett Field, CA 94035-1000 USA

TEL +1 650 604-0068

FAX +1650 604-0673

Marc.m.cohen@nasa.gov

\section{ADDITIONAL SOURCES}

Batty, Michael, (2001, January) "Exploring Isovist Fields: Space and Shape in Architectural and Urban Morphology," Environment and Planning B: Planning and Design, Vol. 28-1, pp. 123-150.

Benaroya, H.; Nagurka, M. (1990). Space Structures Issues in Dynamics \& Control, Aerospace Engineering, Vol. 3, No 4, p. 251-270.

Benaroya, H.; Ettouney, M. (1992, April). Framework for the Evaluation of Lunar Base Structural Concepts, Aerospace Engineering, Vol. 5, No 2, p.187-198.

Benaroya, H.; Ettouney, M. (1992, July). Design \& Construction Considerations for a Lunar Outpost Utility of Earth Design Codes, Aerospace Engineering, Vol. 5, No 3, p. 261-273.

Benaroya, H. (1994). Reliability of Structures for the Moon, Structural Safety, 15. p.67-84.

Benaroya, V.; Bernold, L.; Chua, K-M. (2002, April). Engineering, Design and Construction of Lunar Bases, J Aerospace Engineering, Vol. 15, No. 2, p. 33-45.

Benedikt, M. L., (1979) "To Take Hold of Space: Isovists and Isovist Fields," Environment and Planning B, pp. 47-65.

Blume, Jennifer L., (2002, Dec. 11-12). "Habitability Measurement Research and Development Needs, " Workshop on Space Human Factors Research and Development, Houston, TX: NASA-Johnson Space Center, PowerPoint presentation.

Charles, John B.; White, Ronald J.; (2003, April). Bioastronautics Critical Path Roadmap (BCPR) Baseline Document: A Risk Reduction and Management Approach for Human Spaceflight, Rev. D., Houston, TX: Bioastronautics Program Office, NASA-Johnson Space Center. 
Charles, John, (2000, Feb. 22-23). "Human Space Life Science Critical Path Roadmap: Countermeasures," NASA-JSC, PowerPoint presentation.

Cohen, Marc M. (2002, October). Selected Precepts in Lunar Architecture, IAC-02.Q.4.3.08, 53 International Astronautical Congress, Houston TX, Submitted in a Book Proposal to AIAA, Nov. 2002.

Cohen, Marc M., (2000) "Mars 2008 Surface Habitation Study - Part 5, Mission Design Evaluation Process and Criteria," in Boston, Penelope, Ed., The Case for Mars $V$, American Astronautical Society, Science and Technology Series, Vol. 97, San Diego, CA: Univelt, Inc. pp. 401-418.

Cohen, Marc M., (1990). "Designing Space Habitats for Human Productivity," SAE Transactions, Vol. 99, Journal of Aerospace, Section 1, Part 1., Warrendale, PA: Society of Automotive Engineers, pp. 352-364. (SAE 901204).

Cohen, Marc M., (1998, July 13-16) "Space Habitat Design Integration Issues," SAE-981800, Danvers, MA, 28th ICES.

Cohen, Marc M., (1997). "Design Research Issues for an Interplanetary Habitat," SAE Transactions, Vol. 106, Journal of Aerospace, Section 1. Warrendale, PA: Society of Automotive Engineers, pp. 967-994. (SAE 975632).

Cohen, Marc M.; Kennedy, Kriss J. (1997, November). "Habitats and Surface Construction Technology and Development Roadmap," in A. Noor, J. Malone (Eds.), Government Sponsored Programs on Structures Technology, NASA CP-97-206241, p. 75-96. Washington, DC, USA: National Aeronautics and Space Administration.

Duke, Michael; Benaroya, Haym (1993, May). Lunar Exploration and Development, Special Issue: The Applied Mechanics of a Lunar Base, Applied Mechanics Reviews, 46(5), p 272-277.

Lai, A. Yip Hung; Howe, A. Scott, (2003) "A Kit-of-parts Approach to Pressure Vessels for Planetary Surface
Construction," AIAA-2003-6281, AIAA Space 2003 Conference, San Diego, CA, Sept. 23-25, 2003. Reston VA: AIAA.

Peacock, Brian; Blume, Jennifer; Vallance, Susan; (2002, July) An Index of Habitability, SAE 2002-012501, $32^{\text {nd }}$ ICES.

Stuster, Jack W., (1986) Space Station Habitability Recommendations Based on a Systematic Comparative Analysis of Analogous Conditions, NASA CR 3943: Washington DC: NASA.

Turner, Alsdair; Penn, Alan; (1999, April). "Making Isovists Syntactic: Isovist Integration Analysis," 2nd International Symposium on Space Syntax, Brasilia, Brazil: Universidad de Brasilia.

Wise, J.; Geisendorfer, C.; Tiedje, B.; Lantrip, D.; Johnson, B.; Geisendorfer, G.; (1988). The Quantitative Modeling of Human Spatial Habitability, NASA CR 177501, Moffett Field, CA: NASA-Ames Research Center.

\section{DEFINITIONS, ACRONYMS, ABBREVIATIONS}

AIAA American Institute of Aeronautics and Astronautics.

ARC NASA Ames Research Center

IAA International Astronautics Academy

IAC International Astronomical Congress

ICES International Conference on Environmental Systems

ISS International Space Station

JSC NASA Johnson Space Center, Houston, TX

MSFC NASA Marshall Spaceflight Center

NASA National Aeronautics and Space Administration

OBPR NASA Office of Biological and Physical Research

SAE Society of Automotive Engineers 
TABLE 1. Mass and Volume Calculations by Mission Type, Crew Size, and Duration.

Habot Lunar Base Mission, Crew Size $=4$, Mission Duration = 64 Days

\begin{tabular}{|c|c|c|c|c|c|}
\hline \multicolumn{6}{|l|}{ Lunar Base } \\
\hline Crew Size: & Duration (days): & 64 & & & \\
\hline \multicolumn{6}{|l|}{4} \\
\hline Crew Accommodations System & Mass & Factor & $\begin{array}{l}\text { Mass Subtotal } \\
(\mathrm{kg})\end{array}$ & Volume Factor & $\begin{array}{l}\text { Volume } \\
\text { Subtotal } \\
\text { (m3) }\end{array}$ \\
\hline Galley and Food & & & 887.8 & & 3.809 \\
\hline Food & 2.3 & $\mathrm{~kg} / \mathrm{p} / \mathrm{d}$ & 588.8 & $0.008 \mathrm{~m} 3 / \mathrm{p} / \mathrm{d}$ & 2.048 \\
\hline Freezer(s) & 100 & $\mathrm{~kg}$ & 100 & $0.500 \mathrm{~m} 3$ & 0.500 \\
\hline Conventional ovens & 50 & $\mathrm{~kg}$ & 50 & $0.250 \mathrm{~m} 3$ & 0.250 \\
\hline Microwave ovens & 70 & $\mathrm{~kg}$ & 70 & $0.300 \mathrm{~m} 3$ & 0.300 \\
\hline Cleaning supplies & 0.25 & $\mathrm{~kg} / \mathrm{d}$ & 16.00 & $0.002 \mathrm{~m} 3 / \mathrm{d}$ & 0.115 \\
\hline Sink and spigot & 15 & $\mathrm{~kg}$ & 15 & $0.014 \mathrm{~m} 3$ & 0.014 \\
\hline Dishwasher & 40 & $\mathrm{~kg}$ & 40 & m3 & 1 \\
\hline Cooking/eating supplies & 2 & $\mathrm{~kg} / \mathrm{p}$ & 8 & $0.006 \mathrm{~m} 3 / \mathrm{p}$ & 0.022 \\
\hline Waste Collection & & & 116.7 & & 2.688 \\
\hline System & 45 & $\mathrm{~kg}$ & 45 & $2.150 \mathrm{~m} 3$ & 2.150 \\
\hline Supplies & 0.05 & $\mathrm{~kg} / \mathrm{p} / \mathrm{d}$ & 12.80 & $0.001 \mathrm{~m} 3 / \mathrm{p} / \mathrm{d}$ & 0.333 \\
\hline Contingency collection mittens/bags & 0.23 & $\mathrm{~kg} / \mathrm{p} / \mathrm{d}$ & 58.88 & $0.001 \mathrm{~m} 3 / \mathrm{p} / \mathrm{d}$ & 0.205 \\
\hline Personal Hygiene & & & 109.4 & & 1.824 \\
\hline Shower & 75 & $\mathrm{~kg}$ & 75 & $1.410 \mathrm{~m} 3$ & 1.410 \\
\hline Handwash/mouthwash faucet & 8 & $\mathrm{~kg}$ & 8 & $0.010 \mathrm{~m} 3$ & 0.010 \\
\hline Personal hygiene kit & 1.8 & $\mathrm{~kg} / \mathrm{p}$ & 7.2 & $0.005 \mathrm{~m} 3 / \mathrm{p}$ & 0.020 \\
\hline Hygiene consumables & 0.075 & $\mathrm{~kg} / \mathrm{p} / \mathrm{d}$ & 19.2 & $0.002 \mathrm{~m} 3 / \mathrm{p} / \mathrm{d}$ & 0.384 \\
\hline $\begin{array}{l}\text { Clothing (review notes in factors sheets to } \\
\text { determine trades) }\end{array}$ & & & 229 & & 2.396 \\
\hline Clothing & 69 & $\mathrm{~kg} / \mathrm{p}$ & 69 & $0.224 \mathrm{~m} 3 / \mathrm{p}$ & 0.896 \\
\hline Washing machine & 100 & $\mathrm{~kg}$ & 100 & $\mathrm{~m} 3$ & 1 \\
\hline Clothes dryer & 60 & $\mathrm{~kg}$ & 60 & m3 & 1 \\
\hline Recreational Equipment & & & 100 & & 0.380 \\
\hline Personal stowage & 25 & $\mathrm{~kg} / \mathrm{p}$ & 100 & $0.380 \mathrm{~m} 3$ & 0.380 \\
\hline Housekeeping & & & 175.8 & & 0.626 \\
\hline Vacuum & 13 & $\mathrm{~kg}$ & 13 & $0.070 \mathrm{~m} 3$ & 0.070 \\
\hline Disposable wipes for housecleaning & 0 & $\mathrm{~kg} / \mathrm{p} / \mathrm{d}$ & 0 & $0.000 \mathrm{~m} 3 / \mathrm{p} / \mathrm{d}$ & 0.000 \\
\hline Trash compactor/trash lock & 150 & $\mathrm{~kg}$ & 150 & $0.300 \mathrm{~m} 3$ & 0.300 \\
\hline Trash bags & 0.05 & $\mathrm{~kg} / \mathrm{p} / \mathrm{d}$ & 12.80 & $0.001 \mathrm{~m} 3 / \mathrm{p} / \mathrm{d}$ & 0.256 \\
\hline Operational Supplies and Restraints & & & 130 & & 0.278 \\
\hline Operational supplies & 20 & $\mathrm{~kg} / \mathrm{p}$ & 80 & 0.002 & 0.008 \\
\hline Restraints & 50 & $\mathrm{~kg}$ & 50 & 0.270 & 90.270 \\
\hline
\end{tabular}




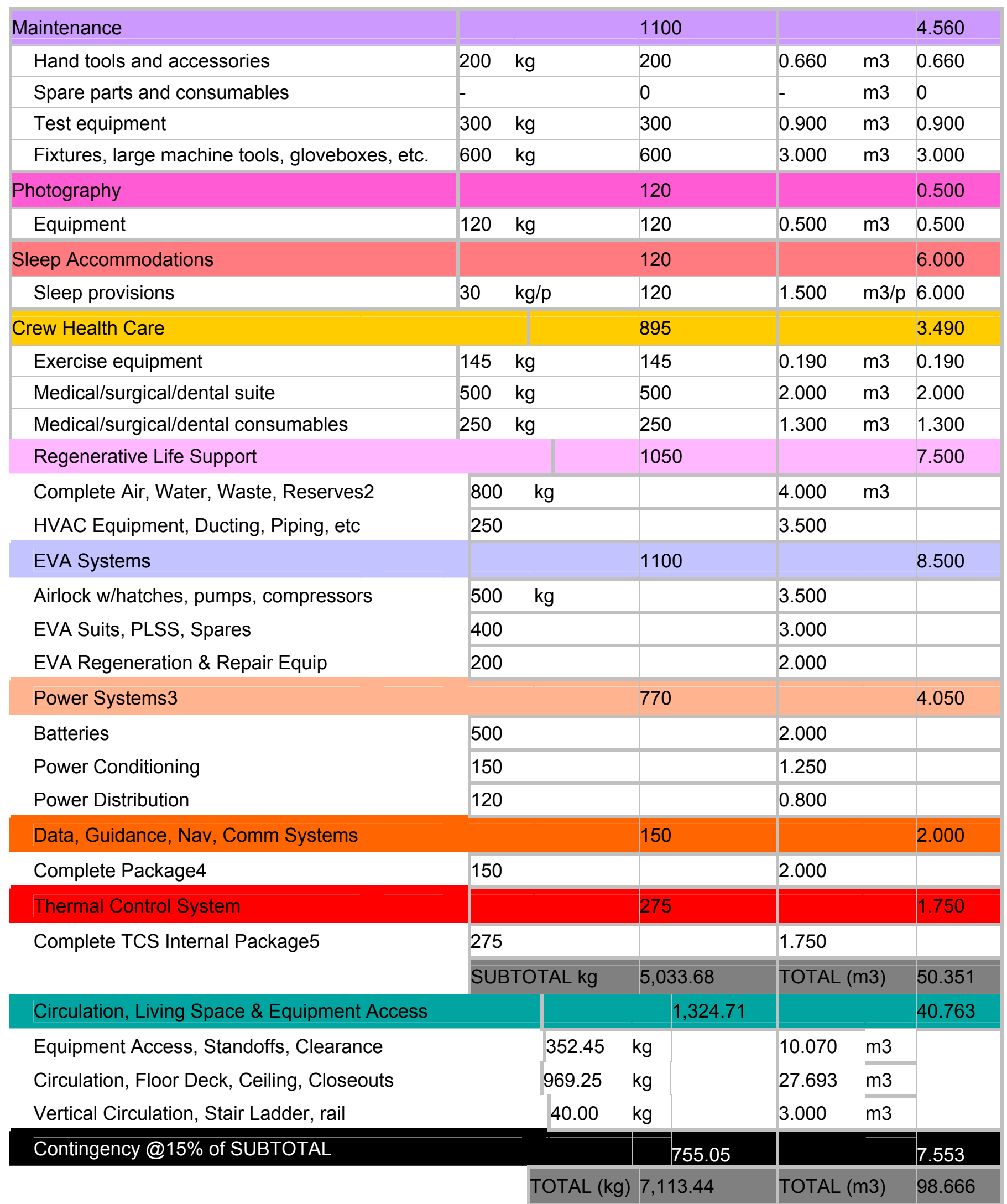

1 Calculations derived from resource model found in Chapter 18, "Crew Accommodations", in Human Spaceflight Mission Analysis and Design. Stilwell, D., Boutros, R., and J. Connolly. New York: McGraw Hill Companies, 1999.

2 From separate, independent estimation analysis for Habot Mobile Lunar Base Module(s)

3 External power supply (e.g. photovoltaic array) excluded

4 External Antennas, Radar, Sensors excluded

5 External radiators excluded 
TABLE 2a. 100m3 Constant Volume Habitat with 6 circumferential pressure ports/penetrations.

\begin{tabular}{|c|c|c|c|c|c|c|c|c|}
\hline \multicolumn{4}{|c|}{100} & \multicolumn{2}{|l|}{$m 3=$} & \multicolumn{3}{|c|}{ Constant Volume } \\
\hline $\begin{array}{l}\text { Cylinder } \\
\text { Diameter, } \\
\mathrm{m}\end{array}$ & \begin{tabular}{|c|} 
Cylinder \\
Circumf $\mathrm{m}$
\end{tabular} & $\begin{array}{l}\text { \# of Pressure } \\
\text { Ports Possible }\end{array}$ & \multicolumn{3}{|c|}{\begin{tabular}{c|c} 
C 1 & Cyl. Cross-Sec. C 2 \\
& $\begin{array}{c}\text { Vol., } 1 \mathrm{~m} \text { high, } \\
\mathrm{m} 3\end{array}$ \\
\end{tabular}} & \multicolumn{2}{|c|}{$\begin{array}{l}\text { Height of C 3 } \\
\text { Ellipsoidal } \\
\text { End Dome, } \mathrm{m}\end{array}$} & $\begin{array}{c}\text { Approx Vol. of } \\
1 \text { Ellips. } \\
\text { Dome, m3 } \\
\end{array}$ \\
\hline Cyl.Dia & |Cyl.Circumf & Num.Press.Ports & & Cyl.Cross.Sec.Vol & & Ht.Ellips.Dome & & Vol.Ellips.Dome \\
\hline 2.50 & 7.85 & 3.14 & & 4.91 & $\mid<<<$ & 0.75 & & 2.45 \\
\hline 2.75 & 8.64 & 3.46 & & 5.94 & <<< & 0.83 & & 3.27 \\
\hline 3.00 & 9.42 & 3.77 & & 7.07 & $\ll<<$ & 0.90 & & 4.24 \\
\hline 3.25 & 10.21 & 4.08 & & 8.30 & $\ll<<$ & 0.98 & e $<<$ & 5.39 \\
\hline 3.50 & 11.00 & 4.40 & & 9.62 & $\ll<<$ & 1.05 & e< & 6.73 \\
\hline 3.75 & 11.78 & 4.71 & & 11.04 & e< & 1.13 & e<< & 8.28 \\
\hline 4.00 & 12.57 & 5.03 & & 12.57 & $\ll<<$ & 1.20 & $\mid<<$ & 10.05 \\
\hline 4.25 & 13.35 & 5.34 & & 14.19 & $\ll<<$ & 1.28 & $k<<$ & 12.06 \\
\hline 4.50 & 14.14 & 5.65 & e< & 15.90 & $<<<$ & 1.35 & $k<<$ & 14.31 \\
\hline 4.75 & 14.92 & 5.97 & $\ll<<$ & 17.72 & $<<<$ & 1.43 & $k<<$ & 16.83 \\
\hline 5.00 & 15.71 & 6.28 & $\ll<<$ & 19.63 & $<<<$ & 1.50 & $<<<$ & 19.63 \\
\hline 5.25 & 16.49 & 6.60 & $<<<$ & 21.65 & & 1.58 & & 22.73 \\
\hline 5.50 & 17.28 & 6.91 & $<<<$ & 23.76 & & 1.65 & & 26.13 \\
\hline 5.75 & 18.06 & 7.23 & e< & 25.97 & & 1.73 & & 29.86 \\
\hline 6.00 & 18.85 & 7.54 & e< & 28.27 & & 1.80 & & 33.93 \\
\hline 6.25 & 19.63 & 7.85 & $\ll<<$ & 30.68 & & 1.88 & & 38.35 \\
\hline 6.50 & 20.42 & 8.17 & $\ll<<$ & 33.18 & & 1.95 & & 43.14 \\
\hline 6.75 & 21.21 & 8.48 & $<<<$ & 35.78 & & 2.03 & & 48.31 \\
\hline & & $\begin{array}{l}\text { CONTROL } \\
\text { ARRAY: }\end{array}$ & & $\begin{array}{c}\text { ENTER } \\
\text { PREFERRED }\end{array}$ & & $\begin{array}{l}\text { CRITERA } \\
\text { VALUES }\end{array}$ & & : \\
\hline Vol.Const & & MinNumPorts & & FL.AreaMin & & CDomMinHt & & Vert.Width \\
\hline 100 & & 6 & & 10 & & 1.00 & & 1 \\
\hline Ratio.Dom & Ht/Dia & PressPort.o.c. & & FL.AreaMax & & CDomMaxHt & & Vert.Back.Clr \\
\hline 0.300 & & 2.50 & & 15 & & 1.50 & & 1.5 \\
\hline
\end{tabular}


TABLE 2b. 100m3 Habitat with 6 circumferential ports/penetrations.

\begin{tabular}{|c|c|c|c|c|c|c|c|c|}
\hline & & & 6 & PORTS & & & & \\
\hline $\begin{array}{l}\text { Ht of Full } \\
\text { Vol. Cyl., } \\
\text { m* }^{*}\end{array}$ & & $\begin{array}{l}2 \text { Domes as \% of } \\
\text { Constant Volume }\end{array}$ & fC 5 & $\begin{array}{c}\text { \# of Floor } \\
\text { Deck Ass'lies }\end{array}$ & C 6 & $\begin{array}{c}\text { Total Vol of } \\
\text { Vert Circul } \\
\text { m3 }\end{array}$ & $\begin{array}{l}\text { Vert. Circul. as } \\
\text { a \% of Vol. }\end{array}$ & C 7 \\
\hline Ht.Str.Cyl & & CDomesPctVol & & Num.Fl.Asslys & & VCircVol & VCircPctVol & \\
\hline 20.37 & & $4.91 \%$ & & 9.05 & & 30.54 & $30.54 \%$ & \\
\hline 16.84 & & $6.53 \%$ & & 7.48 & & 25.25 & $25.25 \%$ & \\
\hline 14.15 & & $8.48 \%$ & & 6.29 & & 21.23 & $21.23 \%$ & \\
\hline 12.05 & & $10.78 \%$ & e< & 5.36 & & 18.09 & $18.09 \%$ & \\
\hline 10.39 & & $13.47 \%$ & e<< & 4.62 & & 15.59 & $15.59 \%$ & \\
\hline 9.05 & & $16.57 \%$ & e<< & 4.02 & & 13.57 & $13.57 \%$ & \\
\hline 7.96 & & $20.11 \%$ & e<< & 3.54 & & 11.95 & $11.95 \%$ & \\
\hline 7.05 & & $24.12 \%$ & $<<<$ & 3.13 & & 10.56 & $10.56 \%$ & $<<<$ \\
\hline 6.29 & $<<<$ & $28.63 \%$ & $<<<$ & 2.79 & & 9.42 & $9.42 \%$ & $\mid<<$ \\
\hline 5.64 & e<< & $33.67 \%$ & e<< & 2.51 & & 8.47 & $8.47 \%$ & e<< \\
\hline 5.09 & e< & $39.27 \%$ & e<< & 2.26 & & 7.63 & $7.63 \%$ & | $<<\mid$ \\
\hline 4.62 & $\ll<<$ & $45.46 \%$ & & 2.05 & $\ll<$ & 6.92 & $6.92 \%$ & $\mid<<<$ \\
\hline 4.21 & $k<<$ & $52.27 \%$ & & 1.87 & $\ll<<$ & 6.31 & $6.31 \%$ & $|<<<|$ \\
\hline 3.85 & & $59.72 \%$ & & 1.71 & $\ll<<$ & 5.77 & $5.77 \%$ & $|<<<|$ \\
\hline 3.54 & & $67.86 \%$ & & 1.57 & $\ll<<$ & 5.30 & $5.30 \%$ & $\mid<<<$ \\
\hline 3.26 & & $76.70 \%$ & & 1.45 & $\ll<<$ & 4.89 & $4.89 \%$ & $|<<<|$ \\
\hline 3.01 & & $86.28 \%$ & & 1.34 & & 4.52 & $4.52 \%$ & $|<<<|$ \\
\hline 2.79 & & $96.62 \%$ & & 1.24 & & 4.19 & $4.19 \%$ & $\mid<<<$ \\
\hline Cvl.Min.Ht & & $\begin{array}{l}\text { CONTROL } \\
\text { ARRAY: } \\
\text { CDomesVol }\end{array}$ & & $\begin{array}{c}\text { ENTER } \\
\text { PREFERRED } \\
\text { NumFLDecks }\end{array}$ & & $\begin{array}{l}\text { CRITERIA } \\
\text { VALUES } \\
\text { FLDeck HT }\end{array}$ & VCircMaxPctVol & \\
\hline 4.00 & & $20 \%$ & & 1.50 & & 2.25 & $10 \%$ & \\
\hline Cyl.Max.Ht & & CDomesMaxVol & & MaxNum.FI.Ass & slys & & Num.Vert.Circ.C & Zores \\
\hline 6.00 & & $35 \%$ & & 2.25 & & & 1 & \\
\hline
\end{tabular}


TABLE 3a. $50 \mathrm{~m} 3$ Constant Volume Habitat with 4 circumferential pressure ports/penetrations.

\begin{tabular}{|c|c|c|c|c|c|c|c|c|}
\hline 50 & $m 3=$ & Constant & & Volume & & & & \\
\hline $\begin{array}{c}\text { Cylinder } \\
\text { Diameter, } \\
m\end{array}$ & \begin{tabular}{|c|} 
Cylinder \\
Circumf \\
$\mathrm{m}$
\end{tabular} & \multicolumn{2}{|c|}{$\begin{array}{l}\text { \# of Pressure C } 1 \\
\text { Ports Possible }\end{array}$} & $\begin{array}{l}\text { Cyl. Cross- } \\
\text { Sec. Vol., } 1 \mathrm{~m} \\
\text { high, m3 }\end{array}$ & C 2 & \multirow{2}{*}{\multicolumn{2}{|c|}{\begin{tabular}{|c|}
$\begin{array}{c}\text { Height of } \\
\text { Ellipsoidal } \\
\text { End Dome } \\
\mathrm{m}\end{array}$ \\
Ht.Ellips.Dome
\end{tabular}}} & $\begin{array}{c}\text { Approx Vol. of } \\
1 \text { Ellips. } \\
\text { Dome, m3 }\end{array}$ \\
\hline Cyl.Dia & $\begin{array}{c}\text { Cyl.Circum } \\
f\end{array}$ & \multicolumn{2}{|l|}{\begin{tabular}{|l} 
Num.Press.Ports \\
\end{tabular}} & \multicolumn{2}{|l|}{ Cyl.Cross.Sec.Vol } & & & Vol.Ellips.Dome \\
\hline 2.50 & 7.85 & 3.14 & & 4.91 & $<<<$ & 0.75 & & 2.45 \\
\hline 2.75 & 8.64 & 3.46 & & 5.94 & $<<<$ & 0.83 & & 3.27 \\
\hline 3.00 & 9.42 & 3.77 & $<<<$ & 7.07 & $<<<$ & 0.90 & & 4.24 \\
\hline 3.25 & 10.21 & 4.08 & $<<<$ & 8.30 & $<<<$ & 0.98 & $<<<$ & 5.39 \\
\hline 3.50 & 11.00 & 4.40 & $<<<$ & 9.62 & $<<<$ & 1.05 & $<<<$ & 6.73 \\
\hline 3.75 & 11.78 & 4.71 & $<<<$ & 11.04 & $<<<$ & 1.13 & $<<<$ & 8.28 \\
\hline 4.00 & 12.57 & 5.03 & $<<<$ & 12.57 & $<<<$ & 1.20 & $<<<$ & 10.05 \\
\hline 4.25 & 13.35 & 5.34 & $<<<$ & 14.19 & $<<<$ & 1.28 & $<<<$ & 12.06 \\
\hline 4.50 & 14.14 & 5.65 & $<<<$ & 15.90 & $<<<$ & 1.35 & $<<<$ & 14.31 \\
\hline 4.75 & 14.92 & 5.97 & $<<<$ & 17.72 & $<<<$ & 1.43 & $<<<$ & 16.83 \\
\hline 5.00 & 15.71 & 6.28 & $<<<$ & 19.63 & $<<<$ & 1.50 & $<<<$ & 19.63 \\
\hline 5.25 & 16.49 & 6.60 & $<<<$ & 21.65 & & 1.58 & & 22.73 \\
\hline 5.50 & 17.28 & 6.91 & $<<<$ & 23.76 & & 1.65 & & 26.13 \\
\hline 5.75 & 18.06 & 7.23 & $<<<$ & 25.97 & & 1.73 & & 29.86 \\
\hline 6.00 & 18.85 & 7.54 & $<<<$ & 28.27 & & 1.80 & & 33.93 \\
\hline 6.25 & 19.63 & 7.85 & $<<<$ & 30.68 & & 1.88 & & 38.35 \\
\hline 6.50 & 20.42 & 8.17 & $<<<$ & 33.18 & & 1.95 & & 43.14 \\
\hline 6.75 & 21.21 & 8.48 & $<<<$ & 35.78 & & 2.03 & & 48.31 \\
\hline & & $\begin{array}{l}\text { CONTROL } \\
\text { ARRAY: }\end{array}$ & & $\begin{array}{c}\text { ENTER } \\
\text { PREFERRED }\end{array}$ & & $\begin{array}{l}\text { CRITERA } \\
\text { VALUES }\end{array}$ & & \\
\hline Vol.Const & & MinNumPorts & & FL.AreaMin & & CDomMinHt & & Vert.Width \\
\hline 50 & & 4 & & 10 & & 1.00 & & 1 \\
\hline Ratio.Dom & 1. Ht/Dia & PressPort.o.c. & & FL.AreaMax & & CDomMaxHt & & Vert.Back.Clr \\
\hline 0.300 & & 2.50 & & 15 & & 1.50 & & 1.5 \\
\hline
\end{tabular}


TABLE 3b. $50 \mathrm{~m}^{3}$ Constant Volume Habitat with 4 circumferential pressure ports/penetrations.

\begin{tabular}{|c|c|c|c|c|c|c|c|c|}
\hline & & 2 & 4 & PORTS & & & & \\
\hline $\begin{array}{l}\text { Ht of Full } \\
\text { Vol. Cyl., } \\
\text { m }^{*}\end{array}$ & C 4 & $\begin{array}{l}2 \text { Domes as } \% \text { of } \\
\text { Constant Volume }\end{array}$ & & $\begin{array}{c}\text { \# of Floor } \\
\text { Deck Ass'lies }\end{array}$ & C 6 & \begin{tabular}{|c|} 
Total Vol of \\
Vert Circul \\
m3
\end{tabular} & $\begin{array}{c}\text { Vert. Circul. as a \% } \\
\text { of Vol. }\end{array}$ & \\
\hline "Ht.Str.Cyl & & $\overline{\overline{\text { CDomesPctVol }}}$ & & Num.Fl.Asslys & & VCircVol & VCircPctVol & \\
\hline 10.19 & & $9.82 \%$ & & 4.53 & & 15.29 & $30.58 \%$ & \\
\hline 8.42 & & $13.07 \%$ & $<<<$ & 3.74 & & 12.62 & $25.25 \%$ & \\
\hline 7.07 & & $16.96 \%$ & $<<<$ & 3.14 & & 10.60 & $21.20 \%$ & \\
\hline 6.03 & $\ll<<$ & $21.57 \%$ & $\ll<<$ & 2.68 & & 9.05 & $18.09 \%$ & \\
\hline 5.20 & $\ll<<$ & $26.94 \%$ & $\ll<$ & 2.31 & & 7.80 & $15.59 \%$ & \\
\hline 4.53 & $\ll<<$ & $33.13 \%$ & $\ll<$ & 2.01 & $\ll<$ & 6.78 & $13.57 \%$ & $\ll<$ \\
\hline 3.98 & & $40.21 \%$ & & 1.77 & $\ll<$ & 5.97 & $11.95 \%$ & \\
\hline 3.52 & & $48.23 \%$ & & 1.57 & $\ll<$ & 5.30 & $10.60 \%$ & \\
\hline 3.14 & & $57.26 \%$ & & 1.40 & & 4.73 & $9.45 \%$ & \\
\hline 2.82 & & $67.34 \%$ & & 1.25 & & 4.22 & $8.44 \%$ & \\
\hline 2.55 & & $78.54 \%$ & & 1.13 & & 3.81 & $7.63 \%$ & \\
\hline 2.31 & & $90.92 \%$ & & 1.03 & & 3.48 & $6.95 \%$ & \\
\hline 2.10 & & $104.54 \%$ & & 0.94 & & 3.17 & $6.35 \%$ & e<< \\
\hline 1.93 & & $119.45 \%$ & & 0.86 & & 2.90 & $5.81 \%$ & e<< \\
\hline 1.77 & & $135.72 \%$ & & 0.79 & & 2.67 & $5.33 \%$ & \\
\hline 1.63 & & $153.40 \%$ & & 0.72 & & 2.43 & $4.86 \%$ & \\
\hline 1.51 & & $172.55 \%$ & & 0.67 & & 2.26 & $4.52 \%$ & $\ll<$ \\
\hline 1.40 & & $193.24 \%$ & & 0.62 & & 2.09 & $4.19 \%$ & $\ll<$ \\
\hline & & $\begin{array}{l}\text { CONTROL } \\
\text { ARRAY: }\end{array}$ & & $\begin{array}{c}\text { ENTER } \\
\text { PREFERRED }\end{array}$ & & & & \\
\hline Cyl.Min.Ht & & CDomesVol & & NumFL.Decks & & FL.Deck.HT & VCircMaxPctVol & \\
\hline 4.00 & & $20 \%$ & & 1.50 & & 2.25 & $13 \%$ & \\
\hline Cyl.Max.Ht & & CDomesMaxVol & & MaxNum.FI.As & sslys & & Num.Vert.Circ.Cores & \\
\hline 6.00 & & $35 \%$ & & 2.25 & & & 1 & \\
\hline
\end{tabular}


TABLE 3b. $50 \mathrm{~m}^{3}$ Constant Volume Habitat with 4 circumferential pressure ports/penetrations.

\begin{tabular}{|c|c|c|c|c|c|c|c|}
\hline \multicolumn{8}{|c|}{ DRTS } \\
\hline $\begin{array}{l}\text { Ht of Full } \\
\text { Vol. Cyl., } \\
\qquad m^{*}\end{array}$ & C4 & 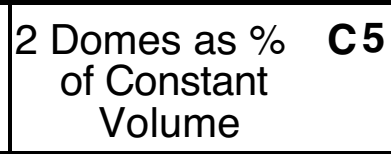 & $\begin{array}{l}\text { \# of Floor } \\
\text { Deck Ass'lies }\end{array}$ & C6 & $\begin{array}{l}\text { Total Vol } \\
\text { of Vert } \\
\text { Circul m3 }\end{array}$ & $\begin{array}{c}\text { Vert. Circul. as a } \\
\% \text { of Vol. }\end{array}$ & C7 \\
\hline \multicolumn{2}{|l|}{ Ht.Str.Cyl } & CDomesPctVol & \multicolumn{2}{|l|}{ Num.FI.Asslys } & VCircVol & \multicolumn{2}{|l|}{ VCircPctVol } \\
\hline 10.19 & & $9.82 \%$ & 4.53 & & $\overline{~ 15.29}$ & $30.58 \%$ & \\
\hline 8.42 & & $13.07 \%$ & 3.74 & & 12.62 & $25.25 \%$ & \\
\hline 7.07 & & $16.96 \%$ & 3.14 & & 10.60 & $21.20 \%$ & \\
\hline 6.03 & $\ll$ & $21.57 \%$ & 2.68 & & 9.05 & $18.09 \%$ & \\
\hline 5.20 & $\ll<$ & $26.94 \%$ & 2.31 & & 7.80 & $15.59 \%$ & \\
\hline 4.53 & $\ll$ & $33.13 \%$ & 2.01 & $\ll$ & 6.78 & $13.57 \%$ & $\ll$ \\
\hline 3.98 & & $40.21 \%$ & 1.77 & $\ll$ & 5.97 & $11.95 \%$ & $\ll$ \\
\hline 3.52 & & $48.23 \%$ & 1.57 & $\ll$ & 5.30 & $10.60 \%$ & $\ll$ \\
\hline 3.14 & & $57.26 \%$ & 1.40 & & 4.73 & $9.45 \%$ & $\ll$ \\
\hline 2.82 & & $67.34 \%$ & 1.25 & & 4.22 & $8.44 \%$ & $\ll<$ \\
\hline 2.55 & & $78.54 \%$ & 1.13 & & 3.81 & $7.63 \%$ & $\ll$ \\
\hline 2.31 & & $90.92 \%$ & 1.03 & & 3.48 & $6.95 \%$ & $\ll$ \\
\hline 2.10 & & $104.54 \%$ & 0.94 & & 3.17 & $6.35 \%$ & $\ll$ \\
\hline 1.93 & & $119.45 \%$ & 0.86 & & 2.90 & $5.81 \%$ & $\ll<$ \\
\hline 1.77 & & $135.72 \%$ & 0.79 & & 2.67 & $5.33 \%$ & $\ll<$ \\
\hline 1.63 & & $153.40 \%$ & 0.72 & & 2.43 & $4.86 \%$ & $\ll<$ \\
\hline 1.51 & & $172.55 \%$ & 0.67 & & 2.26 & $4.52 \%$ & $\ll<$ \\
\hline \multirow[t]{2}{*}{1.40} & & $193.24 \%$ & 0.62 & & 2.09 & $4.19 \%$ & $<<4$ \\
\hline & \multicolumn{2}{|r|}{$\begin{array}{l}\text { CONTROL } \\
\text { ARRAY: }\end{array}$} & $\begin{array}{c}\text { ENTER } \\
\text { PREFERRED }\end{array}$ & & & & \\
\hline \multicolumn{2}{|l|}{ Cyl.Min.Ht } & CDomesVol & NumFL.Decks & & \multicolumn{2}{|c|}{ FL.Deck.HTVCircMaxPctVol } & \\
\hline 4.00 & & $20 \%$ & 1.50 & & 2.25 & $13 \%$ & \\
\hline Cyl.Max.Ht & & CDomesMaxVol & MaxNum.FI.Ass & slys & & Num.Vert.Circ.Cores & \\
\hline 6.00 & & $35 \%$ & 2.25 & & & 1 & \\
\hline
\end{tabular}

